\title{
Análisis del comportamiento diferencial de la práctica anticonceptiva por sexo, origen social y educación en la población urbana de México
}

\author{
Analysis of the differential behavior \\ of contraceptive practice by sex, social origin \\ and education in urban population of Mexico
}

Carole Brugeilles*

Olga Lorena Rojas**

\begin{abstract}
Resumen
En un contexto marcado por un pronunciado descenso de la fecundidad y una extensa difusión de la anticoncepción, como el mexicano, buscamos detectar comportamientos innovadores en el comienzo de la práctica anticonceptiva que podrían cuestionar la tradicional vinculación entre sexualidad, unión y procreación entre la población urbana. Para ello, estudiamos la temporalidad del comienzo de la práctica anticonceptiva en relación con la entrada en unión y el nacimiento de los hijos en la experiencia de hombres y mujeres de tres generaciones y tres estratos sociales. Con los datos de la Encuesta Demográfica Retrospectiva (EDER) de 2011 realizamos diversos análisis demográficos y estadísticos, con los cuales logramos detectar algunos cambios.
\end{abstract}

Palabras clave: práctica anticonceptiva; desigualdad social; género; México.

\footnotetext{
Abstract

In a context characterized by a pronounced decline in fertility and widespread dissemination of contraception, such as the Mexican, we seek to detect innovative behaviors at the beginning of contraceptive practice that could question the traditional

* Universidad París Nanterre. Dirección: 200 Avenue de la République, 92000, Nanterre, Francia. Correo: carole.brugeilles@parisnanterre.fr ORCID: https://orcid.org/0000-00016813-0467

** El Colegio de México, A.C. Dirección: Carretera Picacho Ajusco 20, 14110, Ciudad de México, México. Correo: olrojas@colmex.mx ORCID: https://orcid.org/0000-0002-5374-5378 
vinculation among sexuality, union and procreation among urban population. We study the temporality of the beginning of the contraceptive practice in relation to the entry into union and the birth of the children in the experience of men and women of three generations and three social strata. With data of the Retrospective Demographic Survey (EDER) of 2011 we conducted various demographic and statistical analysis with which we managed to detect some changes.

Keywords: contraceptive practice; social inequality; gender; Mexico.

\section{Introducción}

En México, hasta mediados de los años setenta la fecundidad había permanecido en niveles elevados y en aumento. Entre 1960 y 1970 la tasa global de fecundidad era de siete hijos por mujer. Sin embargo, a partir de la segunda mitad de esa década, descendió de manera rápida y constante a lo largo de los siguientes decenios. De tal suerte que la tasa global de fecundidad para el año 2000 ya era de 2.4 hijos por mujer y actualmente se encuentra cerca de los niveles de reemplazo.

En la literatura especializada sobre el tema, se comenta la necesidad de distinguir dos momentos significativos en este importante proceso de cambio. El primero de ellos, iniciado a principios de la década de los años sesenta, siguió el modelo clásico de la transición demográfica, ocurriendo primero la caída de la fecundidad en las ciudades y entre los grupos sociales más favorecidos en la estructura social, durante los años anteriores a la difusión de los programas nacionales de planificación familiar (Juárez, Quilodrán y Zavala, 1989; Juárez y Quilodrán, 1990). Su origen tiene que ver con un cambio de actitudes y comportamientos femeninos respecto a la familia y la maternidad, que fue adoptado inicialmente por un pequeño grupo de mujeres urbanas que nacieron entre 1937 y 1941. Al parecer se trató de mujeres "pioneras", comparativamente más educadas que las de generaciones previas, cuya primera unión se inició algo más tarde. Estas mujeres empezaron a controlar su descendencia a partir de los 30 años y del nacimiento de su cuarto hijo (Zavala, 1992, 1996; Tuirán, 1994).

El segundo momento se inició en 1974, a raíz del cambio en la política de población y del impulso otorgado por el gobierno mexicano a los programas de planificación familiar, involucrando a sectores sociales menos favorecidos (Zavala, 1996). El resultado fue que la fecundidad empezó a descender de manera acelerada, pues en unos cuantos años, entre 1976 y 1980, la tasa global de fecundidad descendió en poco más de $20 \%$, pasando de 5.51 a 4.37 hijos por mujer. Durante la década de los ochenta, aunque la 
fecundidad continuó disminuyendo a un ritmo más lento, se redujo a 3.8 hijos (Figueroa, 1992). Hacia 1998 ya era del orden de 2.6 hijos, en tanto que actualmente se ha reducido a 2.18 hijos por mujer (Conapo, 2017).

Entre 1976 y 1982, el vínculo cada vez más fuerte entre matrimonios un tanto más tardíos y la formación de familias menos numerosas estuvo estrechamente asociado a un incremento importante de la práctica de métodos modernos de anticoncepción (Zavala, 1992). En 1973, el 12 \% de las mujeres unidas usaba algún método anticonceptivo (Urbina, Palma, Figueroa y Castro, 1984). Si en 1976 una de cada tres mujeres en edad fértil regulaba su fecundidad mediante el uso de algún método anticonceptivo, para 1982 esta proporción se incrementó hasta alcanzar el $48 \%$, en tanto que hacia 1995 ya era del orden de 66.5\% (Hernández, 2001). Actualmente se estima que prácticamente el $80 \%$ de las parejas regula su fecundidad con algún anticonceptivo (Conapo, 2014).

Es importante comentar que estos cambios, relacionados con el control del crecimiento de las descendencias, ocurrieron siempre en el seno de las uniones conyugales y una vez que las parejas habían conformado sus familias. Esto sucedió tanto en el caso de las mujeres "pioneras", que no cuestionaron este modelo (Juárez y Quilodrán, 2009), como en el caso del amplio programa de planificación familiar puesto en marcha a raíz de la política demográfica implementada en el país a partir de 1974 (Brugeilles, 2005).

En este esfuerzo por controlar la natalidad, se promovió un patrón medicalizado en el que predominaron los modernos métodos anticonceptivos. En una primera etapa se difundieron ampliamente las pastillas y la esterilización femenina, y posteriormente se echó mano del dispositivo intrauterino (DIU) (Bronfman, López y Tuirán, 1986). Este patrón de regulación de la fecundidad dejó de lado la utilización de los métodos tradicionales como el ritmo y el retiro, con lo cual se desincentivó la participación masculina en la práctica anticonceptiva.

Con todo ello, nos damos cuenta de que el objetivo de este tipo de programas era limitar la fecundidad en el marco de las uniones conyugales, sin poner en cuestionamiento la relación entre la vida sexual y la vida en unión. En realidad, lo que se estimuló fue la disociación entre la sexualidad y la fecundidad, pero siempre en el seno de las uniones y una vez que las parejas habían comenzado a formar sus descendencias.

En este marco contextual nos proponemos verificar si, después de la experiencia de las "pioneras" y de los más de cuarenta años de la aplicación de una política demográfica de control natal, se ha registrado una evolución de mayor alcance en el país. Buscamos detectar la existencia de 
comportamientos innovadores entre la población mexicana respecto al comienzo de su práctica anticonceptiva.

Nuestro primer objetivo es estudiar las transformaciones en la temporalidad del inicio de la práctica anticonceptiva. Específicamente deseamos saber si la utilización de la anticoncepción continúa siendo un medio para limitar el tamaño de las familias en el seno de las uniones conyugales -sobre todo después del nacimiento del primer hijo- o si están emergiendo comportamientos innovadores que podrían estar cuestionando la tradicional vinculación entre la sexualidad, la vida en unión y la procreación.

En este sentido, nos preguntamos si, a lo largo del tiempo, ¿estamos asistiendo a una creciente disociación entre la vida sexual y la reproducción en el seno de las uniones con hijos? Y más recientemente, ¿es posible que la práctica anticonceptiva empiece a utilizarse por las parejas unidas antes de tener a su primer hijo?, o incluso ¿acaso el uso de la anticoncepción podría preceder a la entrada en unión, dando lugar a una vida sexual premarital sin riesgo de un embarazo? Queremos observar si en México existe un uso más diversificado de la anticoncepción que esté implicando un cambio en la articulación entre sexualidad, unión y procreación. Para dar respuesta a estas preguntas, estudiaremos la temporalidad del comienzo de la práctica anticonceptiva en relación con otros eventos: la entrada en unión y el nacimiento de los hijos.

Nuestro segundo objetivo es analizar, en particular, el tipo del primer método anticonceptivo utilizado, tomando en consideración las normas sociales y médicas que se encuentran detrás de su empleo.

Además de ello, queremos mostrar los distintos patrones del inicio de la práctica anticonceptiva existentes entre las generaciones, los estratos sociales y por sexo. Para ello, intentamos identificar el papel que sobre estos patrones de comportamiento puede tener la socialización que han tenido los individuos en el ambiente de su origen social, además de la influencia que la escolaridad alcanzada puede ejercer en las decisiones en torno a la sexualidad, la vida reproductiva y el uso de la anticoncepción.

Consideramos que la socialización durante la etapa infantil y adolescente, que depende del ambiente social y cultural de cada estrato social, provee de normas y valoraciones sobre la familia, la sexualidad y la reproducción. Por ello, en este estudio nuestro eje de análisis será la desigualdad social, a la que entendemos como contexto sociocultural estructurante y diferenciador de los comportamientos reproductivos y de las prácticas anticonceptivas.

Al mismo tiempo, pensamos que las normativas sociales aprendidas tempranamente, se conjugan a lo largo de la vida con la ausencia o presen- 
cia de los mensajes provenientes de la educación sexual y de la planificación familiar. Por ello, planteamos la hipótesis de que la educación escolar ejerce influencia sobre las valoraciones y comportamientos en torno a la sexualidad, al proveer de nuevos modelos y conocimientos sobre la reproducción y la anticoncepción. Estos elementos permitirían que las personas cuenten con más información y mayor capacidad para la toma de decisiones en torno a su actividad sexual y al control de su fecundidad.

Consideramos entonces que los comportamientos en materia sexual y reproductiva al principio de la vida adulta resultan de la influencia combinada de estos dos aspectos: la socialización obtenida en el medio social de origen y el nivel de escolaridad alcanzado. Además, pensamos que ambas cuestiones pueden ser muy diferentes entre los hombres y las mujeres.

\section{Diferencias sociales en el comienzo de la formación familiar y de la práctica anticonceptiva}

La posposición del comienzo de la vida reproductiva y de la formación familiar es uno de los rasgos característicos de las sociedades desarrolladas. Desde la teoría sociológica se señala que en las sociedades modernas esta transformación forma parte de un proceso de reconstitución de la intimidad que estaría implicando la democratización de las relaciones interpersonales, de la vida diaria, de la esfera privada y de la vida sexual (Giddens, 1998). La intimidad estaría siendo moldeada por el desarrollo de una ideología individualista, en la cual las opciones personales comienzan a proliferar antes que las grupales, que estaban relacionadas con la parentela y con los linajes (Plummer, 2003).

Estas transformaciones sociales y culturales ocurridas en muchos países desarrollados, además de estar relacionadas con la pérdida del control religioso y político sobre la vida de las personas, han implicado una creciente autonomía individual y emancipación económica de las mujeres. Estos cambios se han traducido, para la población en general, en un incremento en la posposición de la edad a la primera unión y del comienzo de la procreación, una mayor incidencia de la procreación en relaciones de cohabitación o extramaritales, además de un incremento en la disolución de las uniones, de las familias reconstituidas y de los hogares con doble proveedor; todos ellos elementos de lo que se denomina como la segunda transición demográfica. En este contexto, los incentivos para retrasar el comienzo de la formación familiar, debido al aumento del costo de oportunidad de tener hijos, son más fuertes entre las personas de estratos sociales mejor posicionados. 
En particular, las mujeres de hogares más aventajados son más proclives a adoptar las pautas reproductivas y familiares modernas, puesto que es muy probable que sus aspiraciones estén fuertemente orientadas hacia el mundo del trabajo (Lesthaeghe, 1995).

En los países de América Latina estas transformaciones comienzan a observarse lentamente y sin mostrar una tendencia generalizada. En específico, se ha detectado un conjunto de países en los que se está verificando el ingreso a la fase de postergación de la fecundidad asociada al avance de la segunda transición demográfica. Este aplazamiento ha comenzado entre las mujeres que cuentan con una escolaridad avanzada. Por ello, se establece que en América Latina existe un patrón polarizado del calendario de la fecundidad según el nivel educativo alcanzado. Es decir, el calendario de entrada a la maternidad se encuentra segmentado por estratos sociales, puesto que hay estratos en los que se comienza a retrasar la maternidad a edades más avanzadas, y otros en los que la población tiene un comportamiento más proclive al inicio temprano. Por ello se establece que el patrón vigente de la fecundidad en América Latina se caracteriza por la existencia de brechas reproductivas. Aunque hay indicios de un gradual incremento de la edad al primer hijo en algunos países, también persiste un componente importante de fecundidad a edades más tempranas. Cuestión que evidencia un escenario de una importante heterogeneidad entre distintos sectores sociales (CEPAL, 2012; Nathan, 2015).

En Uruguay, por ejemplo, algunas investigaciones han reportado una tendencia a la postergación de la fecundidad desde la segunda mitad de la década de los años sesenta del siglo pasado. Sin embargo, también advierten que este fenómeno no se ha generalizado en todos los grupos sociales y que el nivel educativo alcanzado por la población está fuertemente asociado al calendario de entrada a la maternidad y a la paternidad. Se concluye entonces que en la sociedad uruguaya coexisten patrones divergentes que reflejan una creciente polarización social de las trayectorias femeninas y masculinas en su transición al primer hijo. La postergación de la fecundidad es más frecuente entre las mujeres y los hombres con mayores niveles educativos y de contextos socioeconómicos más favorables; y al mismo tiempo persiste una proporción relativamente estable de mujeres y hombres con menor nivel de educación que, en cada cohorte, ingresan a la maternidad y paternidad de manera temprana (Fostik, Fernández y Varela, 2014; Nathan, 2015).

En Brasil se ha dado cuenta de la existencia de desigualdades sociales en la difusión de los cambios en el comportamiento reproductivo. Al respecto, se señala que la edad media al inicio de la vida reproductiva varía según la clase social y tiende a aumentar en los estratos sociales mejor situados. 
La diferencia entre la edad al primer hijo entre las mujeres de clases sociales más pobres y aquellas de la clase social más favorecida es cercana a los cinco años, semejante al periodo de tiempo medio necesario para cursar una educación universitaria. En este sentido, se comenta que estas diferencias se encuentran estrechamente vinculadas a las desigualdades de clase en el uso de métodos anticonceptivos. En particular, las clases acomodadas disponen de una mejor calidad de atención a su salud sexual y reproductiva, así como de un abanico más diversificado de métodos anticonceptivos, al compararlas con aquellas mujeres de contextos sociales más empobrecidos (Reis, 2015).

En México, se han realizado diversos esfuerzos de investigación sobre el comportamiento reproductivo de la población y respecto al papel que desempeñó la anticoncepción en el descenso de los niveles de fecundidad. En este sentido, han destacado aquellas investigaciones que han considerado a la desigualdad social como eje analítico y que consideran que las distintas condiciones de vida y de socialización en los diferentes estratos sociales terminan por definir desiguales panoramas de opciones, decisiones y comportamientos de las personas en torno a su reproducción (García y Oliveira, 1990).

Desde esta perspectiva, se ha observado que los estratos más empobrecidos de la sociedad se caracterizan por tener altos niveles de fecundidad, en buena medida, porque tienen menos oportunidades de acceder a una educación formal, así como a la información sobre la reproducción y su control (Mier y Terán y Rabell, 1984; García y Oliveira, 1990).

Con este esquema analítico se ha analizado el avance de la práctica anticonceptiva en los diferentes estratos sociales del país. Así, a comienzos de la década de los ochenta del siglo pasado se detectaron diversas pautas de comportamiento. En los grupos sociales urbanos más acomodados se observó que la práctica anticonceptiva se encontraba muy difundida, mientras que los grupos sociales urbanos marginados mostraban un nivel de uso de anticoncepción por debajo de la media nacional, pero sin alejarse demasiado; en tanto que la población rural se caracterizó por tener las menores proporciones de usuarios de algún método anticonceptivo (Bronfman, López y Tuirán, 1986).

Estudios más recientes, que han retomado esta perspectiva, han dado cuenta de que la desigualdad social se expresa actualmente en distintos patrones de inicio a la vida sexual, marital y reproductiva entre las mujeres y los hombres pertenecientes a diferentes estratos sociales (Zavala, 2005; Páez y Zavala, 2016). En particular, se ha observado entre las mujeres de estratos medios y altos una tendencia a posponer estos eventos y a iniciar su actividad sexual antes de unirse. Comienza a detectarse entonces en el país 
una mayor heterogeneidad en las trayectorias sexuales, maritales y reproductivas de la población femenina, ligada a la persistente desigualdad social (Solís, Gayet y Juárez, 2008).

En lo que respecta al papel de la escolaridad, sobre todo en el caso de las mujeres, se sabe que los mayores niveles de instrucción contribuyen a la conformación de un proceso de autonomía que implica un cambio de valores y amplitud en las alternativas a la vida familiar. Estos cambios estarían asociados a un retraso del comienzo de la vida en unión entre las mujeres mexicanas (Mier y Terán, 2016).

Por otro lado, también se ha observado en los ámbitos urbanos que los hombres y las mujeres con mejores niveles de escolaridad tienen mayor diversidad de opciones vitales y acceso a nuevas normativas respecto a la sexualidad, la vida conyugal y la reproducción, respecto a sus pares rurales y con poca escolaridad. Al parecer, en estos contextos sociales favorecidos comienza a existir una mayor aceptación de las experiencias sexuales prematrimoniales, la posposición de las uniones y la utilización de métodos anticonceptivos (Amuchástegui, 2001; Szasz, 2001). Sin embargo, a pesar de estos avances, las diferencias entre hombres y mujeres siguen prevaleciendo puesto que, si se compara con la experiencia masculina, entre las mujeres todavía existe una escasa distancia entre el comienzo de la vida sexual y el principio de la procreación, así como entre la entrada en unión y la procreación (Sazsz, 2001, 2008; Brugeilles y Samuel, 2005; Welti, 2005; Solís, Gayet y Juárez, 2008; Brugeilles y Rojas, 2016).

\section{La fuente de información y los métodos de investigación}

Para este estudio utilizamos datos de la Encuesta Demográfica Retrospectiva (EDER) de 2011, que estudia a las generaciones nacidas en: 1951-1953, 1966-1968 y 1978-1980. Su población se circunscribe únicamente a la que habita en las 32 áreas urbanas y metropolitanas autorrepresentadas de la Encuesta Nacional de Ocupación y Empleo (ENOE). Es decir, se trata de una población eminentemente urbana al momento de la encuesta; por ello, en este estudio estamos imposibilitadas para hablar de las poblaciones que radican en las comunidades rurales e indígenas del país. Esta es una limitación de la EDER 2011 y, por lo tanto, de nuestro análisis, puesto que nos impedirá realizar generalizaciones para la totalidad de la población mexicana. ${ }^{1}$

${ }^{1}$ Con un diseño probabilístico, estratificado y por conglomerados, el tamaño de la muestra total fue de 3200 individuos, conformada por 1000 individuos en cada una de las dos 
Por otro lado, conviene señalar que las generaciones nacidas entre 1951-1953 ya habían comenzado la formación de sus familias antes de la puesta en marcha del Programa Nacional de Planificación Familiar. En cambio, las cohortes intermedia y joven han vivido en un contexto de amplia legitimación social de la práctica anticonceptiva.

Es importante aclarar que los reportes de los individuos -hombres y mujeres- muchas veces hacen referencia al método anticonceptivo utilizado por sus parejas. En este sentido, es posible que gran parte de los reportes masculinos hagan referencia a los métodos utilizados por sus compañeras. Sin embargo, la experiencia en el levantamiento de encuestas entre la población masculina ha demostrado que ellos son buenos informantes respecto a los métodos utilizados por ellos o por sus parejas. La información que los hombres aportan sobre el uso de métodos que requieren de la participación masculina (como el condón, el retiro, el calendario o la vasectomía) es sumamente valiosa porque las mujeres pueden subestimar y subdeclarar el uso de estos métodos debido a que ellas no los usan o pueden no valorarlos como métodos anticonceptivos.

Conviene señalar en este tema que debido a que el cuestionario de la EDER no está adaptado para captar una práctica anticonceptiva ocasional o con una duración menor de un año, es posible que existan algunos problemas de subdeclaración. Al respecto, hay que mencionar que en la declaración de datos retrospectivos puede existir un problema de memoria y de reconstrucción del pasado en las personas encuestadas. Sin embargo, diversos estudios han demostrado que este tipo de problemas son realmente menores en las encuestas retrospectivas biográficas, porque al acordarse de distintos eventos y de su ocurrencia relativa en el tiempo, las personas pueden recordar mejor sus experiencias pasadas (Le Coeur, Im-em, Koetsawang y Lelièvre, 2005).

En la realización de este estudio hemos utilizado el análisis de supervivencia con el método de Kaplan Meier (calendarios de los eventos), además de regresiones logísticas: binomial y multinomial.

primeras cohortes y 1200 en la tercera, y con una distribución homogénea entre hombres y mujeres. La tasa de no respuesta fue de $8.4 \%$ y se realizaron 2932 entrevistas completas que contemplan un total de 132763 años de vida. Limitándose a las tres cohortes elegidas, con una tolerancia de al menos dos años, la base incluye a 2840 personas y 128507 años de vida. La muestra fue seleccionada a partir de la encuesta de hogares de la ENOE, cuya información es proporcionada por una persona del hogar. Esta persona no siempre es el informante directo y por ello la información puede ser imprecisa. Al respecto, se recomienda consultar en la página del INEGI/Encuestas en hogares/EDER 2011 los documentos: "Descriptor de archivos", "Instructivo de llenado" y "Criterios de validación". 
Para dar cuenta de las diferencias sociales, hemos utilizado el índice de origen social (IOS) diseñado por Patricio Solís, quien para su construcción toma en cuenta las características de la familia de origen de ego cuando tenía 15 años: el nivel de educación y la ocupación de sus padres, además de los recursos económicos del hogar parental (Solís, 2016). Este índice de origen social nos permitió distribuir a los individuos en tres grupos o estratos sociales que se distribuyen entre las generaciones y corresponden a distintos ámbitos sociales empobrecidos, intermedios o favorecidos. Así, los estratos sociales considerados para este estudio son: bajo, medio y alto.

Además, tomamos en consideración la escolaridad alcanzada por los individuos, ${ }^{2}$ que, asociada con el estrato social, nos permite establecer hipótesis relacionadas con el acceso diferencial al conocimiento sobre la sexualidad, la reproducción y los métodos anticonceptivos, así como a representaciones y normas que estarían vinculadas a comportamientos más o menos innovadores. De tal suerte que el nivel escolar alcanzado permite, por un lado, acceder a información más completa y precisa sobre la sexualidad, la reproducción y la anticoncepción; y, por otro lado, puede contribuir a modificar las representaciones, normas, expectativas y oportunidades sociales. Ambas cuestiones finalmente ejercerán influencia sobre las decisiones en torno a la formación familiar.

\section{La prevalencia del uso de anticoncepción}

Las proporciones de individuos que han utilizado algún método anticonceptivo (Gráfica 1) nos permiten confirmar que la difusión de esta práctica en el país se ha extendido ampliamente a través de las generaciones y en todos los estratos sociales. Se puede observar que en cualquier generación y en cualquier estrato social, más de la mitad de los hombres y de las mujeres han empleado la anticoncepción en el curso de su vida.

La encuesta permite observar la adopción de algún método hasta los 30 años en cada generación. Este límite se extiende a los 42 para la generación intermedia y a los 55 para la más avanzada, lo que nos permite tener una idea más completa de su experiencia anticonceptiva.

En términos generales, se constata que a través de las generaciones hay un ligero aumento en el uso de anticoncepción, tanto entre la población

${ }^{2}$ La EDER permite conocer exactamente el nivel escolar alcanzado por las personas y construir niveles de escolaridad agregados. El nivel de educación se puede considerar a distintas edades y, en particular, al momento del primer uso de un método anticonceptivo. 
masculina como entre la femenina. A pesar de ello, se pueden detectar diferencias por sexo puesto que, en todas las generaciones, a los 30 años las mujeres habían comenzado su práctica anticonceptiva con mayor frecuencia que los hombres. Sin embargo, no ocurre lo mismo en la generación 19511953 a la edad de 42 años y de 55 años, ya que son los hombres quienes más frecuentemente han usado algún método. En el caso de las mujeres, la adopción de un método después de los 30 años es poco común. Es más frecuente en los hombres, puesto que sus compañeras son más jóvenes.

\section{Gráfica 1}

Proporciones de hombres y mujeres que han usado un método anticonceptivo

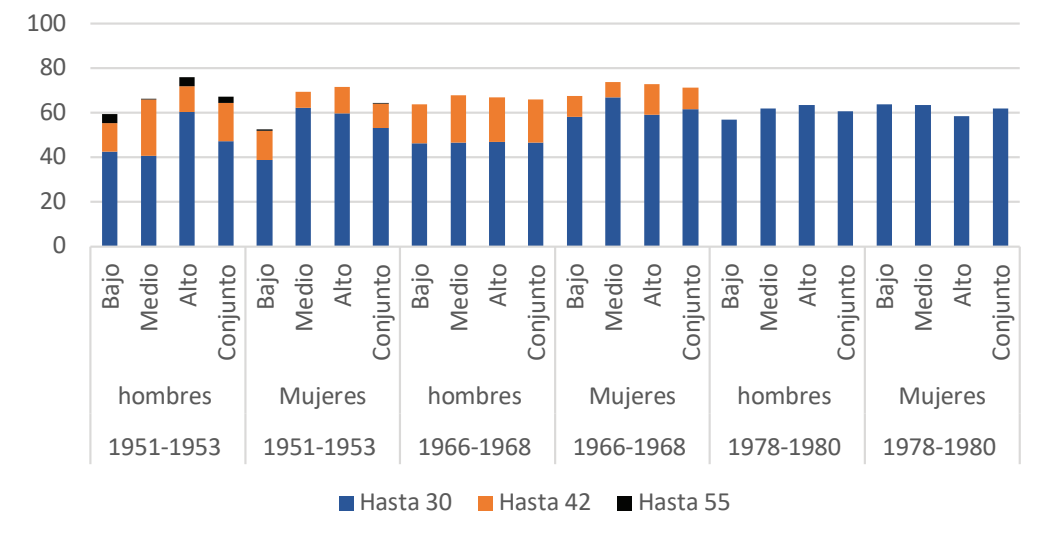

Nota: La muestra cuenta con 863 individuos de las generaciones 1951-1953 (426 hombres y 437 mujeres), 876 de las generaciones $1966-1968$ (425 y 451) y 1041 de las generaciones 1978-1980 (505 y 536).

Fuente: Elaboración propia con base en la EDER, 2011.

Por otra parte, se puede constatar que la amplia difusión de la práctica anticonceptiva a través de las generaciones ha contribuido a disminuir las diferencias entre los estratos sociales. Estas diferencias eran más evidentes en la cohorte más antigua (1951-1953) puesto que la población de estrato bajo se encontraba claramente retrasada en el comienzo de su práctica anticonceptiva al compararla con aquella de los otros dos estratos sociales. En esta misma cohorte también se observan diferencias en la experiencia de los estratos alto y medio, y esto ocurre a los 30 años, como a los 42 y a los 55 años. 
En la generación intermedia (1966-1968) las diferencias sociales disminuyen notablemente, tanto a los 30 como a los 42 años, aun cuando las mujeres de estrato bajo se encuentran un poco rezagadas respecto a las de estrato medio. Es interesante destacar que, a los treinta años, las mujeres de los estratos medio y alto de esta cohorte habían utilizado algún método con mayor frecuencia que aquellas de esos mismos estratos en la cohorte más joven. Esto probablemente se deba a una modificación en el calendario de formación familiar entre estas últimas, puesto que pueden haberlo retrasado.

\section{Cuadro 1}

Edades medianas de los cinco eventos

\begin{tabular}{|c|c|c|c|c|c|c|c|}
\hline Cohorte & Sexo & $\begin{array}{c}\text { Estrato } \\
\text { social }\end{array}$ & Unión & $\begin{array}{c}1^{e r} \\
\text { hijo }\end{array}$ & $2^{o}$ hijo & $\begin{array}{c}3^{e r} \\
\text { hijo }\end{array}$ & Anticoncepción \\
\hline \multirow{8}{*}{$\begin{array}{l}1951- \\
1953\end{array}$} & Hombre & Bajo & 23 & 24 & 27 & 31 & 36 \\
\hline & \multirow{7}{*}{ Mujer } & Medio & 23 & 25 & 27 & 32 & 33 \\
\hline & & Alto & 24 & 26 & 30 & 37 & 28 \\
\hline & & Conjunto & 24 & 25 & 28 & 33 & 31 \\
\hline & & Bajo & 19 & 20 & 23 & 26 & 37 \\
\hline & & Medio & 19 & 20 & 23 & 26 & 27 \\
\hline & & Alto & 22 & 23 & 27 & 34 & 27 \\
\hline & & Conjunto & 20 & 21 & 24 & 28 & 29 \\
\hline \multirow{8}{*}{$\begin{array}{l}1966- \\
1968\end{array}$} & Hombre & Bajo & 22 & 25 & 29 & 37 & 33 \\
\hline & \multirow{7}{*}{ Mujer } & Medio & 24 & 25 & 30 & 39 & 32 \\
\hline & & Alto & 26 & 28 & 32 & - & 32 \\
\hline & & Conjunto & 24 & 26 & 30 & & 32 \\
\hline & & Bajo & 20 & 21 & 25 & 34 & 28 \\
\hline & & Medio & 21 & 23 & 27 & - & 26 \\
\hline & & Alto & 24 & 25 & 29 & - & 28 \\
\hline & & Conjunto & 22 & 23 & 27 & & 27 \\
\hline \multirow{8}{*}{$\begin{array}{l}1978- \\
1980\end{array}$} & Hombre & Bajo & 22 & 25 & 30 & - & 29 \\
\hline & \multirow{7}{*}{ Mujer } & Medio & 23 & 25 & 30 & - & 26 \\
\hline & & Alto & 28 & 29 & - & - & 28 \\
\hline & & Conjunto & 24 & 26 & & & 28 \\
\hline & & Bajo & 21 & 21 & 26 & - & 25 \\
\hline & & Medio & 22 & 23 & 28 & - & 26 \\
\hline & & Alto & 26 & 27 & - & - & 29 \\
\hline & & Conjunto & 22 & 23 & 28 & & 26 \\
\hline
\end{tabular}

Fuente: Elaboración propia con base en la EDER, 2011. 
Estas evoluciones se aprecian con mayor claridad al analizar las edades medianas al primer uso de anticoncepción (Cuadro 1). En términos generales se puede distinguir claramente un calendario bastante tardío entre las poblaciones masculina y femenina de las generaciones 1951-1953. A través de las generaciones, la edad mediana a la primera anticoncepción tiende a disminuir notoriamente entre los hombres y las mujeres de los estratos bajo y medio. Llama la atención en el estrato alto el caso de las mujeres, entre quienes la edad mediana se incrementa en las generaciones más jóvenes. Esto mismo ocurre entre los hombres de estrato alto de las generaciones intermedias respecto a las más avanzadas. Estas evoluciones pueden explicarse por un cambio en el calendario de otros eventos, tales como la unión y el nacimiento de los hijos, que se han retrasado. Además de ello, debe notarse que en este estrato social ya se habían observado desde las generaciones mayores (1951-1953) edades medianas relativamente jóvenes (28 años para el caso masculino y 27 años para el femenino) al comienzo de la práctica anticonceptiva.

A raíz de estas evoluciones inversas, la diferencia entre las edades medianas al primer uso de anticoncepción entre los estratos sociales tiende a disminuir a través de las generaciones. De tal suerte que en las generaciones 1951-1953 la brecha entre el estrato bajo y alto es de 8 años entre los hombres y de 10 años entre las mujeres, en las generaciones 1966-1968 la diferencia se ha reducido a un año en el caso masculino, y en el caso femenino ya se han igualado las edades medianas al primer uso de anticoncepción. La brecha aumenta nuevamente para las mujeres nacidas en 1978-1980, puesto que entre las de estrato bajo esta edad continúa rejuveneciendo, en tanto para las mujeres de estrato alto ha aumentado, en el marco de un calendario más tardío de otros eventos en la conformación de sus familias.

\section{El calendario del comienzo de la práctica anticonceptiva, de la primera unión y del nacimiento de los hijos}

Para este análisis consideramos las proporciones de las personas que a cada edad han vivido una primera unión, un primer, segundo o tercer nacimiento de los hijos y el comienzo de su práctica anticonceptiva. Para ello hemos utilizado el método de Kaplan Meier (Gráfica 2).

En las generaciones más avanzadas (1951-1953) se aprecia una estrecha vinculación entre la primera unión y el nacimiento del primer hijo, cualquiera que sea el estrato social. En el caso de las mujeres, esta vinculación es más fuerte que entre los hombres, cuestión que refleja las representacio- 
nes y normas sociales bastante conservadoras respecto a la entrada en unión y la reproducción para esas generaciones. Se aprecia un incremento de las proporciones de hombres y mujeres que tienen un segundo hijo en los estratos sociales bajo y medio. Y, en cambio, se observa una reducción entre las personas de estrato alto.

\section{Gráfica 2}

Proporciones de hombres y mujeres que han tenido una primera unión, un primer, segundo y tercer nacimiento, o un primer uso de anticoncepción a la edad $x$ por cohorte y estrato social

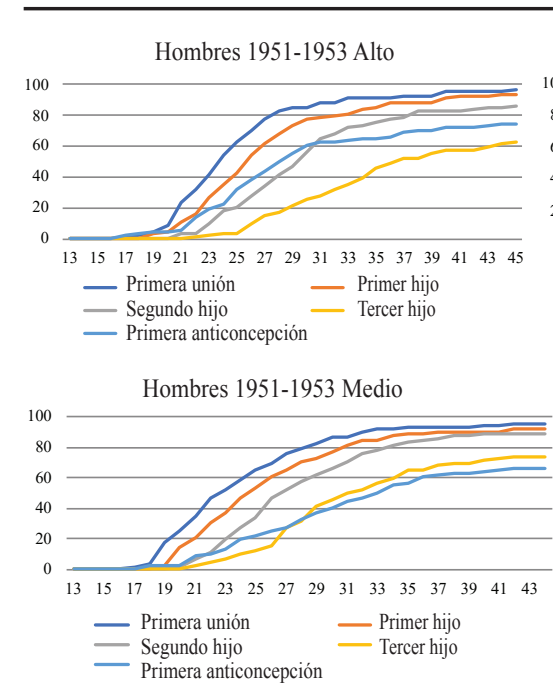

Hombres 1951-1953 Bajo

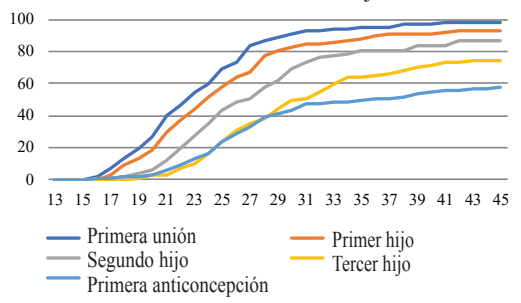

Mujeres 1951-1953 Alto

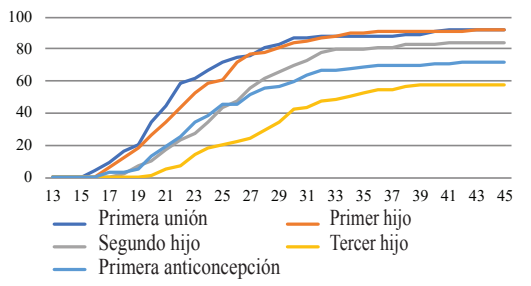

Mujeres 1951-1953 Medio

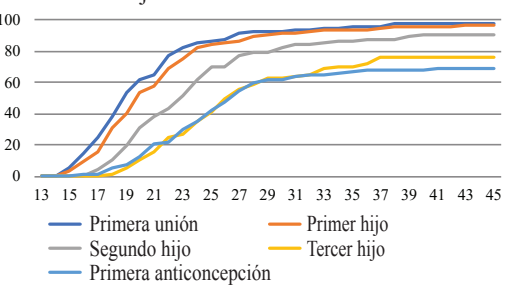

Mujeres 1951-1953 Bajo

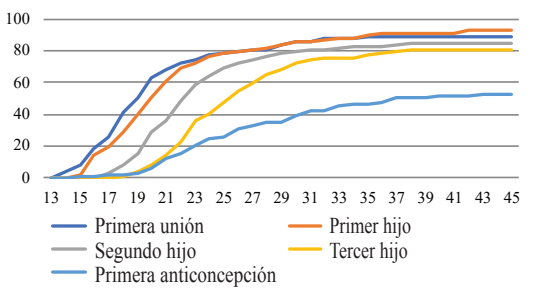


Hombres 1966-1968 Alto

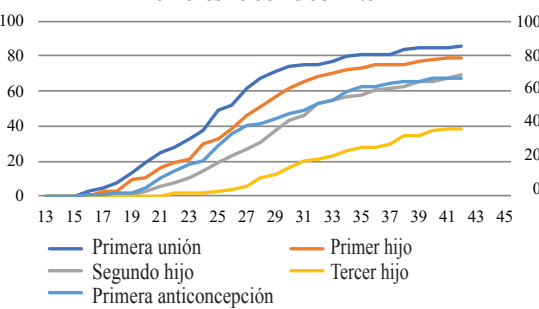

Hombres 1966-1968 Medio

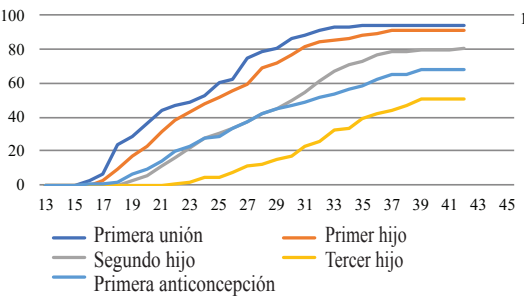

Hombres 1966-1968 Bajo

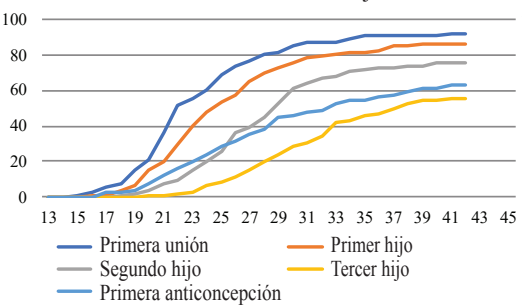

Hombres 1978-1980 Alto

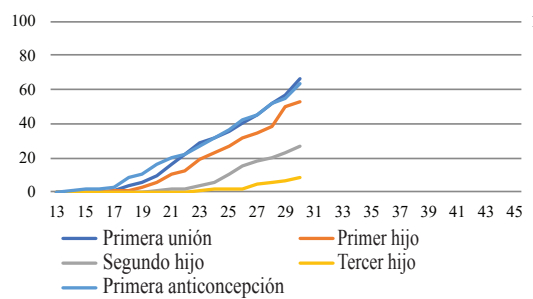

Mujeres 1966-1968 Alto

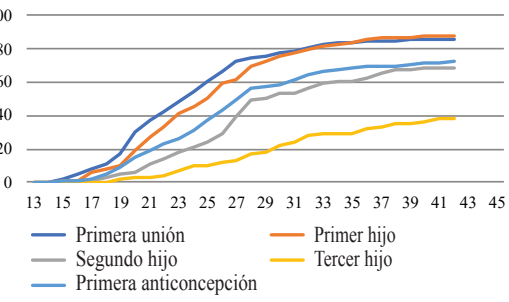

Mujeres 1966-1968 Medio

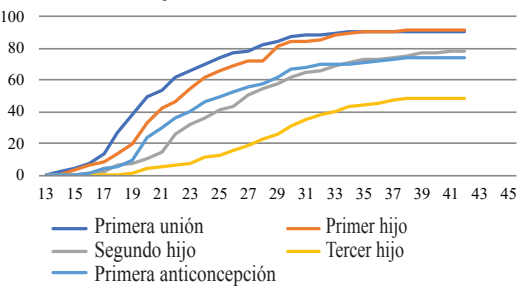

Mujeres 1966-1968 Bajo

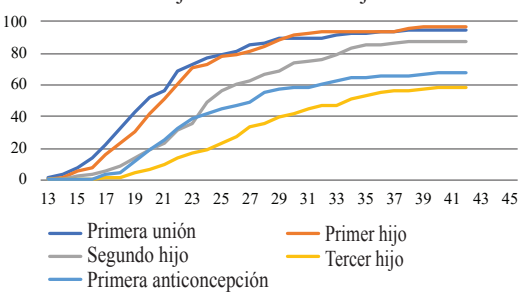

Mujeres 1978-1980 Alto

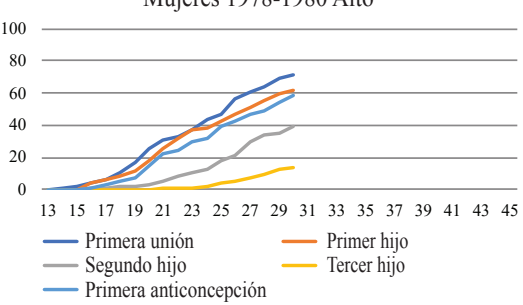




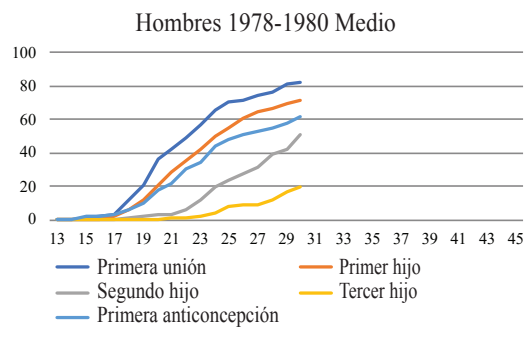

Hombres 1978-1980 Bajo

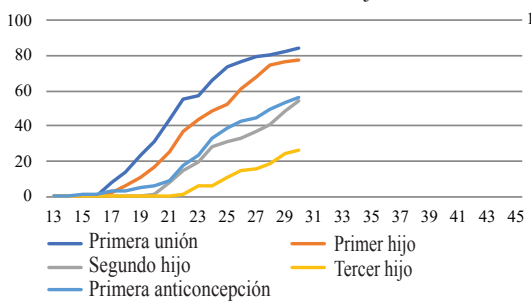

Mujeres 1978-1980 Medio

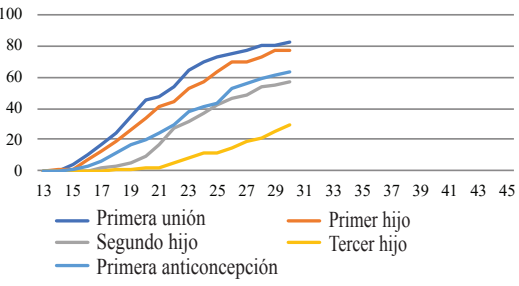

Mujeres 1978-1980 Bajo

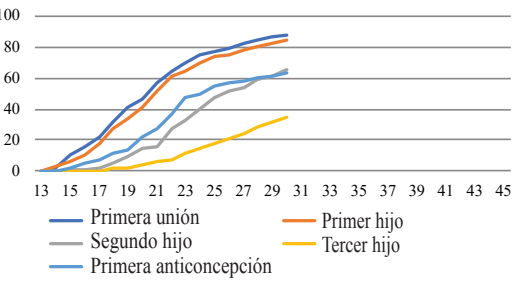

Fuente: Elaboración propia con base en la EDER, 2011; método Kaplan Meier.

Es notorio, por otra parte, que en el estrato alto se registre una posposición del calendario de la primera unión y, por lo tanto, del nacimiento del primer hijo, especialmente en el caso masculino. Esta diferencia social es muy importante y notoria, al tiempo que confirma lo que se ha dicho respecto al claro deseo de reducir el tamaño de las familias entre los grupos sociales más favorecidos.

En esta generación, el comienzo de la práctica anticonceptiva es bastante tardío. En el caso de los hombres de estrato bajo su calendario es próximo al nacimiento del tercer hijo, en tanto que en el estrato medio es similar al calendario del segundo hijo, aunque se acerca más al del nacimiento del tercer hijo. En cambio, en el estrato alto, es más precoz que el calendario del nacimiento del segundo hijo.

Podemos decir que se observan modelos de comportamiento diferenciados según el estrato social puesto que el comienzo de la práctica anticonceptiva tiende a aparecer más tempranamente en la formación de la descendencia conforme mejora el nivel social. Los hombres de estrato alto se distinguen de aquellos de los otros estratos por tener un calendario de uso de anticoncepción más precoz en relación con los otros eventos.

En la generación intermedia (1966-1968) se mantiene la estrecha vinculación entre la unión y el primer hijo; de hecho, en el caso de las mujeres 
de estrato bajo estos dos calendarios casi se superponen y se fusionan a partir de los 22 años. Mientras que en los estratos medio y alto la superposición de las curvas se observa a partir de los 30 años, al tiempo que se registra una unión un tanto más tardía.

Nuevamente, tal como se había observado en la generación mayor, los hombres y las mujeres de estrato alto tienden a posponer la entrada en unión y, por lo tanto, los otros eventos de la formación familiar. Se detecta además una reducción de las proporciones de mujeres que tienen un segundo hijo entre los estratos sociales, en tanto que entre los hombres estas proporciones aumentan entre el estrato bajo y medio, pero se reducen entre este estrato y el alto. También hay una reducción de la proporción de las personas que han tenido un tercer hijo, y este descenso es más marcado en los estratos medio y alto.

En esta misma generación intermedia, el calendario del comienzo de la práctica anticonceptiva es más temprano respecto a la generación más avanzada y en relación con los demás eventos de la formación familiar. Esta evolución se observa en todos los estratos sociales, incluso entre la población del estrato bajo, que en la generación más avanzada se encontraba rezagado. El inicio de la anticoncepción se aproxima al calendario del segundo hijo, como se había observado en el estrato alto de la generación mayor. Estos notables cambios muy probablemente se deban a la intensa y generalizada difusión de la planificación familiar en el país.

En la cohorte más joven (1978-1980) se prolongan los cambios observados y las diferencias sociales vuelven a aparecer. En el estrato alto se mantiene la posposición a la entrada en unión y de la llegada del primer hijo, entre las mujeres como entre los hombres. Estas evoluciones indican actitudes y valoraciones sociales claramente diferenciadas respecto al comportamiento de las poblaciones de los estratos medio y bajo.

En los estratos medio y bajo se observan proporciones idénticas de quienes han tenido un segundo hijo, tanto en el caso masculino como en el femenino. En tanto que en el estrato alto dichas proporciones disminuyen, además de que el calendario de la llegada del segundo hijo es más tardío. Las proporciones de quienes tienen un tercer hijo se han reducido en todos los estratos sociales, aunque esta evolución es más notoria en los estratos medio y alto.

En esta misma generación se confirma la tendencia a una práctica anticonceptiva cada vez más temprana respecto a los otros eventos, tanto en el caso masculino como en el femenino. Su calendario es bastante cercano al nacimiento del segundo hijo, pero tiende a aproximarse al nacimiento del primer hijo conforme mejora la situación social de las personas. En el caso masculino ya se ha acercado al calendario de la primera unión. 
Con todo ello, podemos decir que, entre las tres cohortes estudiadas, el calendario del inicio de la práctica anticonceptiva es cada vez más próximo al del nacimiento del primer hijo, después de la primera unión. En cada generación se observan diferencias sociales importantes, puesto que las poblaciones de estrato alto se mantienen a la vanguardia en el avance de estas transformaciones. Al tiempo que entre los hombres se aprecian comportamientos un tanto más innovadores que entre las mujeres, sobre todo en las generaciones nacidas en 1951-1953 y en 1978-1980.

Una manera un tanto más sintética para observar estas evoluciones es el análisis de las edades medianas de los cinco eventos estudiados y situar el comienzo de la práctica anticonceptiva en relación con los otros cuatro eventos (Cuadro 1).

Para el conjunto de la generación mayor (1951-1953), la edad mediana al comienzo de la práctica anticonceptiva se ubica entre las edades medianas al segundo y tercer hijos en el caso masculino, y es superior a la edad mediana a la llegada del tercer hijo en el caso femenino. Pueden distinguirse además algunas diferencias sociales importantes, puesto que en los estratos bajo y medio la edad mediana al primer uso de anticoncepción es más elevada que la edad mediana al tercer hijo. En tanto, en el estrato alto de esta generación los hombres se distinguen porque su edad mediana, al inicio de la anticoncepción, se encuentra entre el nacimiento del primer y del segundo hijos; en tanto que entre las mujeres es idéntica a la del segundo hijo. En esta generación, son los hombres de estrato alto quienes notoriamente tienen comportamientos realmente innovadores.

En el conjunto de la cohorte intermedia (1966-1968), la edad mediana al uso de un método es posterior a la del segundo hijo en el caso de los hombres, mientras que entre las mujeres es la misma que la del segundo hijo. En esta cohorte también se aprecian diferencias sociales, ya que entre los hombres y las mujeres del estrato bajo, esta edad se encuentra entre la del segundo y del tercer hijo, al igual que entre los hombres de estrato medio. En tanto que para los hombres de estrato alto, esta edad ya es la misma que la del segundo hijo. Las mujeres de estrato medio y alto se distinguen porque su edad mediana a la anticoncepción está entre aquella del primer y segundo hijo. Por ello, en esta generación son las mujeres quienes muestran un comportamiento más novedoso.

Por lo que toca al conjunto de la generación más joven (1978-1980), se observa que la edad mediana al comienzo de la práctica anticonceptiva es superior a la del primer hijo, pero inferior a la del segundo hijo, y esto ocurre en casi todos los estratos sociales, tanto entre los hombres como entre las mujeres. La excepción notable en esta generación es el caso de los hombres 
de estrato alto, quienes se distinguen por mostrar un comportamiento realmente innovador, puesto que su edad mediana al uso de anticoncepción es la misma que la de la primera unión.

Así, podemos decir que estamos asistiendo a un cambio generacional importante en la utilización de anticoncepción, puesto que es cada vez más precoz en relación con los demás eventos de la trayectoria de formación familiar entre la población mexicana. Este cambio está marcado fuertemente en términos sociales, y en ello las poblaciones de estrato alto se distinguen por ser precursoras, en tanto que las de estrato bajo se encuentran rezagadas todavía respecto a estos cambios.

\section{El comienzo de la práctica anticonceptiva en las trayectorias de formación familiar}

Para entender mejor estas evoluciones, ahora nos aproximamos al análisis de las trayectorias de formación familiar de los individuos, que consideran tres eventos: la primera unión, el nacimiento del primer hijo y el comienzo de la práctica anticonceptiva. Presentamos solamente una clasificación según el primer evento experimentado. Comparamos las trayectorias hasta los treinta años, edad alcanzada por todas las cohortes en estudio (Cuadro 2).

En términos generales, la primera unión continúa siendo el primer evento de las trayectorias familiares de manera preponderante en todas las generaciones, estratos sociales y en ambos sexos. Lo cual indica que en México este patrón de formación familiar tradicional ha permanecido a través del tiempo y continúa predominando. Sin embargo, si consideramos a las trayectorias hasta los 30 años, empieza a ser menos frecuente entre las generaciones y comienza a mostrar algunas variaciones dependiendo del estrato social. En todas las generaciones, tanto en el caso masculino como en el femenino, este patrón es menos frecuente en el estrato social alto. Sin embargo, hay que notar que en las generaciones mayores no se observan diferencias estadísticamente significativas.

Esta diferencia se explica principalmente por un efecto del calendario puesto que, a los treinta años, la proporción de aquellos que no han experimentado ningún evento aumenta entre las generaciones y es más frecuente en el estrato alto. Esto confirma lo que habíamos visto en los análisis previos, que en este grupo social existe una clara tendencia a posponer la entrada en unión y, por consiguiente, la conformación de sus familias. 


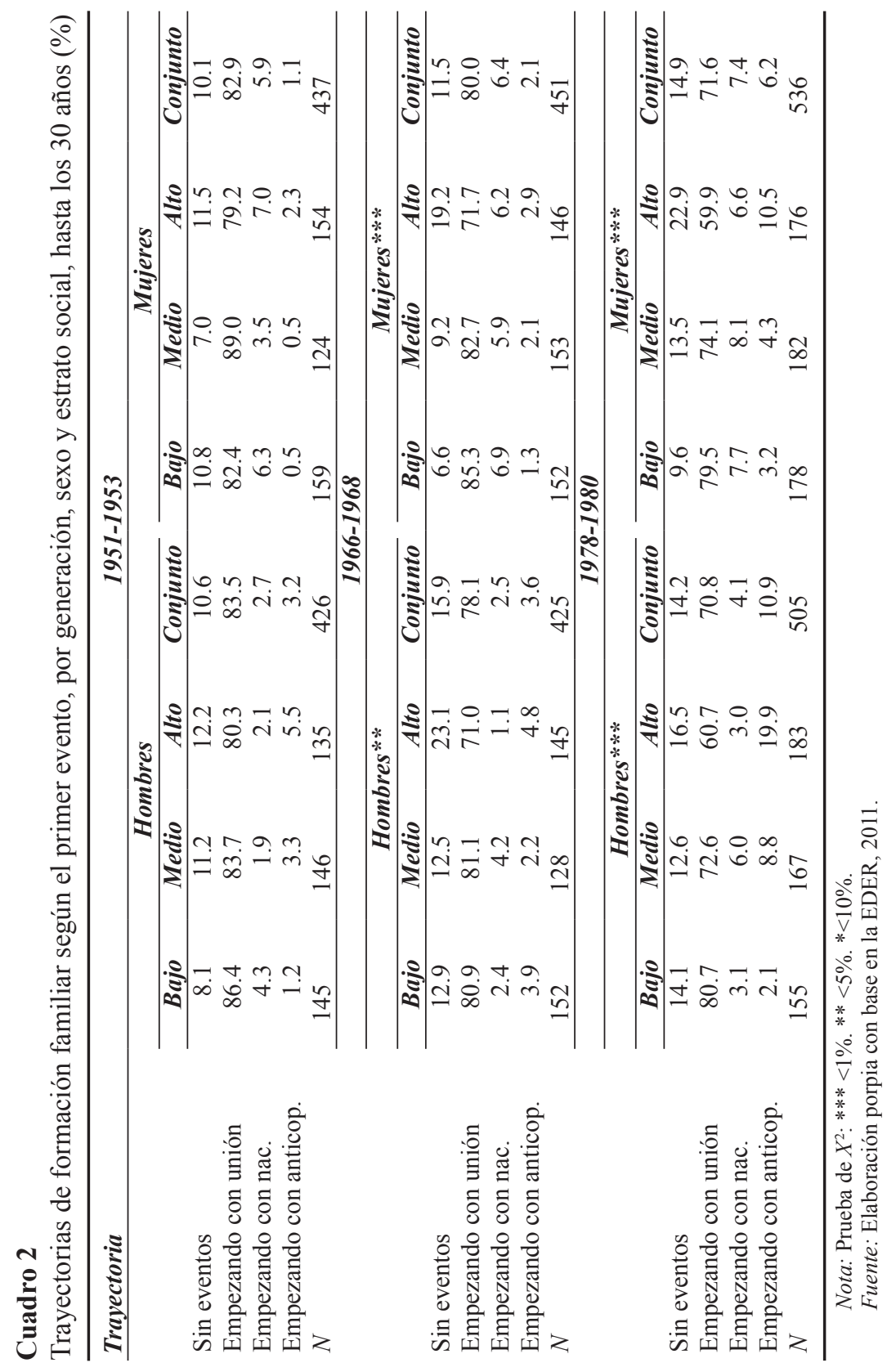


Las trayectorias que comienzan con un nacimiento son poco frecuentes en todas las generaciones y estratos sociales. Son más frecuentemente declaradas por las mujeres. Por su lado, las trayectorias que empiezan por el uso de anticoncepción son igualmente raras, aunque tienden a incrementarse a lo largo de las generaciones, sobre todo en la generación más joven (1978-1980). Estas trayectorias son siempre más reportadas entre los hombres que entre las mujeres, además de que en todas las generaciones son cada vez más frecuentes en los tres estratos sociales, aunque entre las cohortes más antiguas las diferencias no son significativas. En esta evolución es destacable el incremento particular observado en la generación más joven de hombres de estrato alto (19\%).

Para tratar de dar cuenta con mayor detalle de los comportamientos innovadores, ahora analizamos en particular las trayectorias que dan cuenta del uso de un primer método anticonceptivo antes de la primera unión y antes de haber procreado un hijo (Cuadro 3). Con ello buscamos detectar la posibilidad de que en algunos grupos sociales del país esté comenzando a registrarse una disociación entre la vida sexual, la entrada en unión y la procreación. Para afinar aún más este análisis tratamos de distinguir entre:

a) Aquellos individuos que han comenzado su práctica anticonceptiva sin haberse unido (separación entre sexualidad y unión).

b) Aquellos individuos que han comenzado su práctica anticonceptiva sin haber tenido un hijo (separación entre sexualidad y procreación). Entre ellos, unos usaron anticoncepción sin haberse unido (separación entre sexualidad y procreación fuera de las uniones) y otros han utilizado algún método anticonceptivo estando ya unidos, pero sin haber tenido un hijo. En esta experiencia se estaría hablando de la posibilidad de una vida conyugal disociada de la procreación (separación entre sexualidad y procreación en el seno de las uniones).

La utilización de anticoncepción antes de haberse unido es un evento relativamente raro en las generaciones mayor e intermedia. Sin embargo, esta posibilidad tiende a ser cada vez más frecuente a través de las generaciones, siendo más común encontrarla en el estrato alto. En ese sentido, son notorias las proporciones observadas en la generación más joven (1978-1980) de hombres (21.8\%) y mujeres $(15.5 \%)$ de estrato alto. Como se observa, esta experiencia es más declarada por los hombres que por las mujeres. 


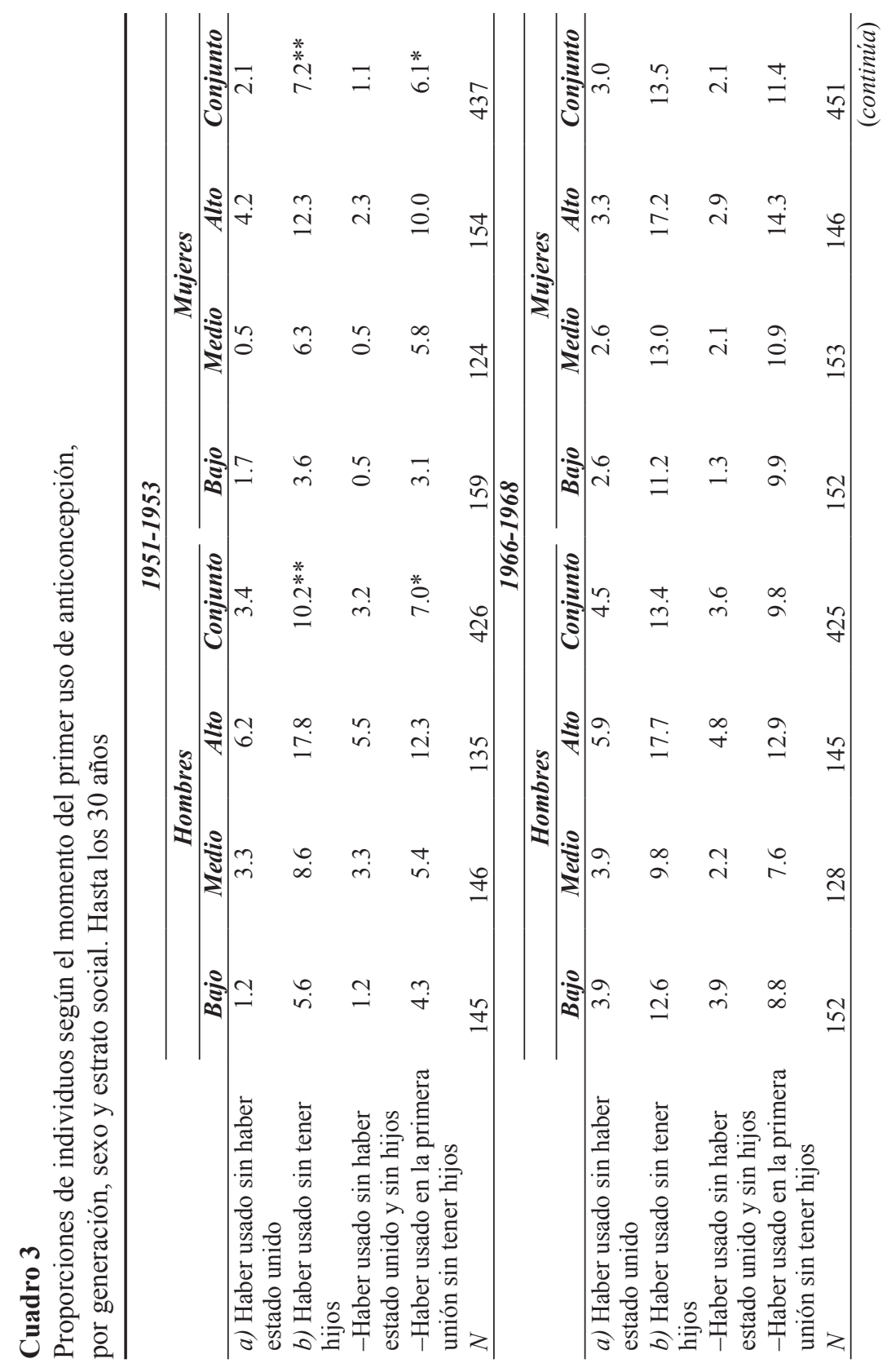




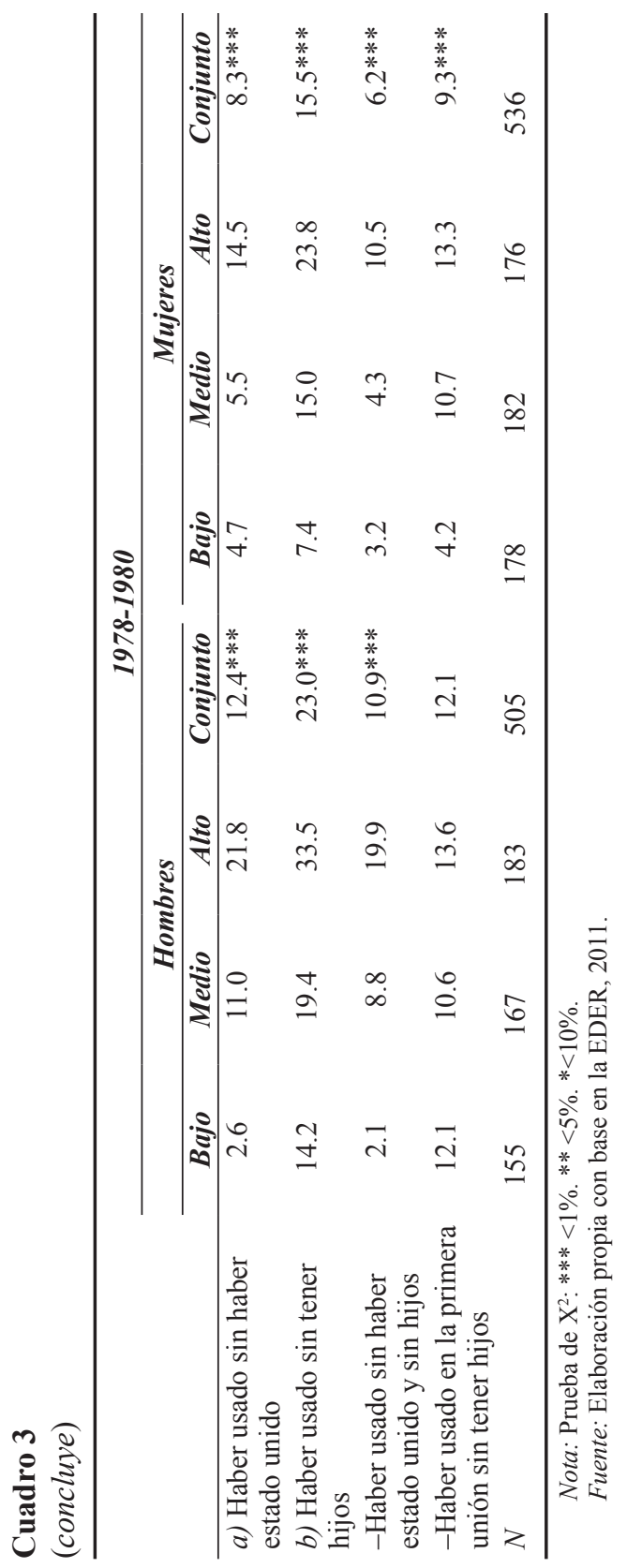


Este tipo de comportamientos estaría denotando una ruptura con las normas sociales y médicas prevalecientes en la sociedad mexicana respecto a la utilización de los métodos anticonceptivos entre los jóvenes de estratos sociales más favorecidos. Entre ellos empieza a darse la posibilidad de vivir una vida sexual premarital minimizando el riesgo de un embarazo. Estas nuevas experiencias están emergiendo lentamente y, aun dentro de su contexto social, son todavía escasas, aunque siempre más frecuentes entre los hombres que entre las mujeres.

El comienzo de la práctica anticonceptiva antes de haber tenido un hijo involucra dos situaciones muy diferentes. Por un lado, la posibilidad de usar algún método sin tener hijos y sin estar unidos -al igual que haber usado algún método antes de la unión- es un comportamiento muy escaso en las dos cohortes más avanzadas, sobre todo entre las mujeres. Aunque es ligeramente más frecuente en el estrato alto. Comienza a incrementarse en la cohorte 1966-1968, sobre todo en el estrato alto y particularmente en el caso masculino. Sin embargo, las diferencias por estrato social no son significativas.

Y, por otro lado, está el uso de anticoncepción en el seno de las uniones conyugales antes de haber procreado al primer hijo. Al parecer, la posibilidad de disfrutar de un tiempo para la vida conyugal sin hijos es todavía una experiencia excepcional, puesto que en el país sigue siendo preponderante la conformación de la descendencia una vez que se ha entrado en unión. Sin embargo, este comportamiento novedoso comienza a difundirse poco a poco entre los grupos sociales más favorecidos a través de las generaciones. Hay que tomar en cuenta, sin embargo, que para las generaciones intermedias las diferencias no son significativas. En cambio, sí lo son para las generaciones más antiguas y para las mujeres de las cohortes más jóvenes.

Si se combinan las dos posibilidades, usar anticoncepción antes de la unión y dentro de la unión, pero sin tener hijos, se observa claramente que se trata de una evolución generacional con una notoria diferenciación social, puesto que $33 \%$ de los hombres y $23 \%$ de las mujeres de la generación más joven y de estrato alto han comenzado su práctica anticonceptiva sin haber tenido hijos.

Para comprender mejor el origen de estas evoluciones, buscamos conocer qué elementos estarían detrás de un comportamiento innovador respecto al uso de anticoncepción entre la población mexicana que hablaría de un distanciamiento respecto a la normativa social tradicional y las normas médicas establecidas por los programas nacionales de planificación familiar. Para ello, estudiamos la probabilidad de comenzar a utilizar algún 
método anticonceptivo sin haber tenido hijos ${ }^{3}$ por medio de un modelo de regresión logística. Cabe recordar que esta experiencia agrupa los casos de quienes iniciaron el uso de algún método antes de unirse (sin hijos) y de quienes lo hicieron estando unidos, pero sin haber procreado a su primer hijo. Deseamos conocer el efecto que pudieran ejercer diversas variables sociodemográficas en este comportamiento novedoso: la cohorte de nacimiento, el sexo, la combinación del estrato social con el nivel de escolaridad y la edad a la unión (Cuadro 4).

\section{Cuadro 4}

Efecto de algunas variables sociodemográficas en la probabilidad de haber usado un primer método anticonceptivo sin haber tenido hijos hasta los 30 años. Modelo logístico

\begin{tabular}{|c|c|c|c|}
\hline Características & & $\begin{array}{c}\text { Razones } \\
\text { de momios }\end{array}$ & Sig. \\
\hline \multirow[t]{3}{*}{ Cohorte } & $1951-1953$ & 0.673 & $* *$ \\
\hline & $1978-1980$ & 1.449 & $* * *$ \\
\hline & 1966-1968 (ref.) & & \\
\hline \multirow[t]{2}{*}{ Sexo } & Mujer & 0.777 & $* *$ \\
\hline & Hombre (ref.) & & \\
\hline \multirow{9}{*}{$\begin{array}{l}\text { Estrato social } \\
\text { y escolaridad }\end{array}$} & Alto / preparatoria o más & 3.701 & $* * *$ \\
\hline & Alto / secundaria & 2.407 & $*$ \\
\hline & Alto / primaria o sin estudios & 2.555 & $* *$ \\
\hline & Medio / preparatoria o más & 2.337 & $* * *$ \\
\hline & Medio / secundaria & 1.692 & $*$ \\
\hline & Medio / primaria o sin estudios & 1.310 & \\
\hline & Bajo / preparatoria o más & 2.089 & $* *$ \\
\hline & Bajo / secundaria & 1.482 & \\
\hline & Bajo / primaria o sin estudios (ref.) & & \\
\hline \multirow[t]{3}{*}{ Edad a la unión } & Nunca unido hasta los 30 años & 0.859 & \\
\hline & A los 23 o más años & 1.737 & $* * *$ \\
\hline & Antes de los 23 años (ref.) & & \\
\hline
\end{tabular}

Likelihood ratio $=143.9228$

$\mathrm{DDL}=13 * * *$

$N=2780$

$* \mathrm{p}<.05 ; * * \mathrm{p}<.01 ; * * * \mathrm{p}<.001$.

Fuente: Elaboración propia con base en la EDER, 2011.

${ }^{3}$ La utilización de la anticoncepción antes de la unión es un evento realmente marginal en la mayoría de las poblaciones de las tres cohortes y de los tres estratos sociales estudiados para poder construir un modelo de regresión confiable.

Estudios Demográficos y Urbanos, vol. 35, núm. 2 (104), mayo-agosto, 2020, pp. 293-332 http://dx.doi.org/10.24201/edu.v35i2.1847 
En particular, al estudiar el estrato social con el nivel de escolaridad buscamos analizar el efecto combinado de ambos tipos de socialización sobre las decisiones reproductivas y anticonceptivas de las personas. Como hemos dicho antes, la socialización primaria en el origen social puede verse enriquecida, matizada e, incluso, modificada de manera importante por la formación escolar, que provee nuevas informaciones y valoraciones en torno a la vida sexual, reproductiva y familiar.

Los resultados muestran que la probabilidad de tener este tipo de comportamiento aumenta a través de las generaciones, puesto que es menos frecuente entre la población de la cohorte mayor (1951-1953) que en la cohorte más joven (1978-1980), ambas con respecto a la cohorte intermedia (1966-1968).

Los hombres reportan más que las mujeres este tipo de comportamiento, y el estrato alto siempre muestra probabilidades más elevadas de usar anticoncepción sin haber tenido hijos respecto a los otros dos estratos.

La educación escolar también influye en estos comportamientos. Cualquiera que sea el estrato social, la escolaridad de preparatoria amplía la posibilidad de que las personas comiencen su práctica anticonceptiva sin haber tenido hijos. Por ello, este efecto se presenta en los estratos alto, medio y bajo en combinación con una escolaridad de preparatoria. En cambio, la escolaridad de secundaria parece tener este efecto entre los individuos de estrato alto y medio, pero no de estrato bajo. Entonces, observamos que la combinación del estrato social y la escolaridad tiene un efecto muy importante sobre los comportamientos de las personas respecto a la sexualidad y el control de la fecundidad. Si pertenecen al estrato alto, cualquiera que sea su nivel escolar, tienen más propensión a tener un comportamiento novedoso, que se incrementa conforme aumenta el nivel educativo. En el estrato medio la escolaridad de preparatoria aumenta esta propensión, al igual que la de secundaria, aunque en menor escala. En cambio, en el estrato bajo solamente un nivel escolar de preparatoria permitiría la conformación de nuevos comportamientos. Unirse después de los 22 años favorece este comportamiento innovador, puesto que el deseo de procrear al primer hijo más tarde, llevaría a buscar la posibilidad de tener más tiempo para disfrutar de una vida sexual sin hijos. Por todo ello, podemos decir que la ruptura entre sexualidad-unión-reproducción es más probable entre la población masculina, de la cohorte más joven, de estrato alto y con elevados niveles de escolaridad.

Analizamos ahora la elección del tipo de primer método anticonceptivo de los individuos en cada generación y estrato social hasta la edad de 30 años (Cuadro 5). En general, podemos observar un cambio muy claro del 
primer método a través de las generaciones. Las pastillas anticonceptivas fueron cediendo su lugar al dispositivo intrauterino (DIU), en tanto que se mantuvo el uso de los métodos naturales entre las dos generaciones más avanzadas, para finalmente reducir su prevalencia entre los más jóvenes. La esterilización femenina se ha mantenido vigente entre las generaciones, mientras que las inyecciones, al igual que el condón, han ido aumentando con el tiempo.

En la cohorte mayor (1951-1953) los hombres declararon más frecuentemente haber utilizado, en orden de importancia, las pastillas, los métodos naturales y el DIU; mientras que las mujeres utilizaron con mayor frecuencia las pastillas, el DIU y los métodos naturales. En la cohorte intermedia (1966-1968) se aprecian notables cambios y se observa una clara coincidencia en las declaraciones de hombres y mujeres, ya que los métodos más empleados fueron: el DIU, las pastillas y los métodos naturales. La cohorte más joven (1978-1980) muestra mayor diversidad en el empleo de anticoncepción, pues los hombres declararon haber usado más frecuentemente los condones, después el DIU y en tercer lugar las pastillas o las inyecciones. Las mujeres, en cambio, usaron con mayor frecuencia el DIU, después las pastillas, siguiendo los condones.

Estos cambios reflejan dos dinámicas en la difusión y uso de anticoncepción entre la población mexicana (Brugeilles, 2005; 2011). Las generaciones pioneras buscaron por sus propios medios el acceso a las pastillas anticonceptivas, esfuerzo en el que se encontraron con los programas de planificación familiar impulsados por el gobierno, y en los cuales se promovió en sus primeras etapas, precisamente, el uso de las pastillas. Al evolucionar los programas de planificación familiar se ofrecieron métodos mucho más medicalizados y dirigidos principalmente a la población femenina. Entre ellos destaca el DIU y la esterilización femenina. Hay que destacar que en este cambio de estrategia se buscó ejercer un control médico y clínico sobre las usuarias, disminuyendo así la intervención de las mujeres y los hombres sobre la regulación de su fecundidad (Brugeilles, 2011).

A pesar de ello, a través de las generaciones se detecta la existencia de individuos que de alguna manera eluden el control médico de los amplios y generalizados programas de planificación familiar, al continuar utilizando los métodos naturales. De hecho, se aprecian entre la población masculina más joven experiencias que alejan su vida sexual del control médico y social al incrementar de manera notable el uso del condón y convertirlo en el método más utilizado entre ellos. 


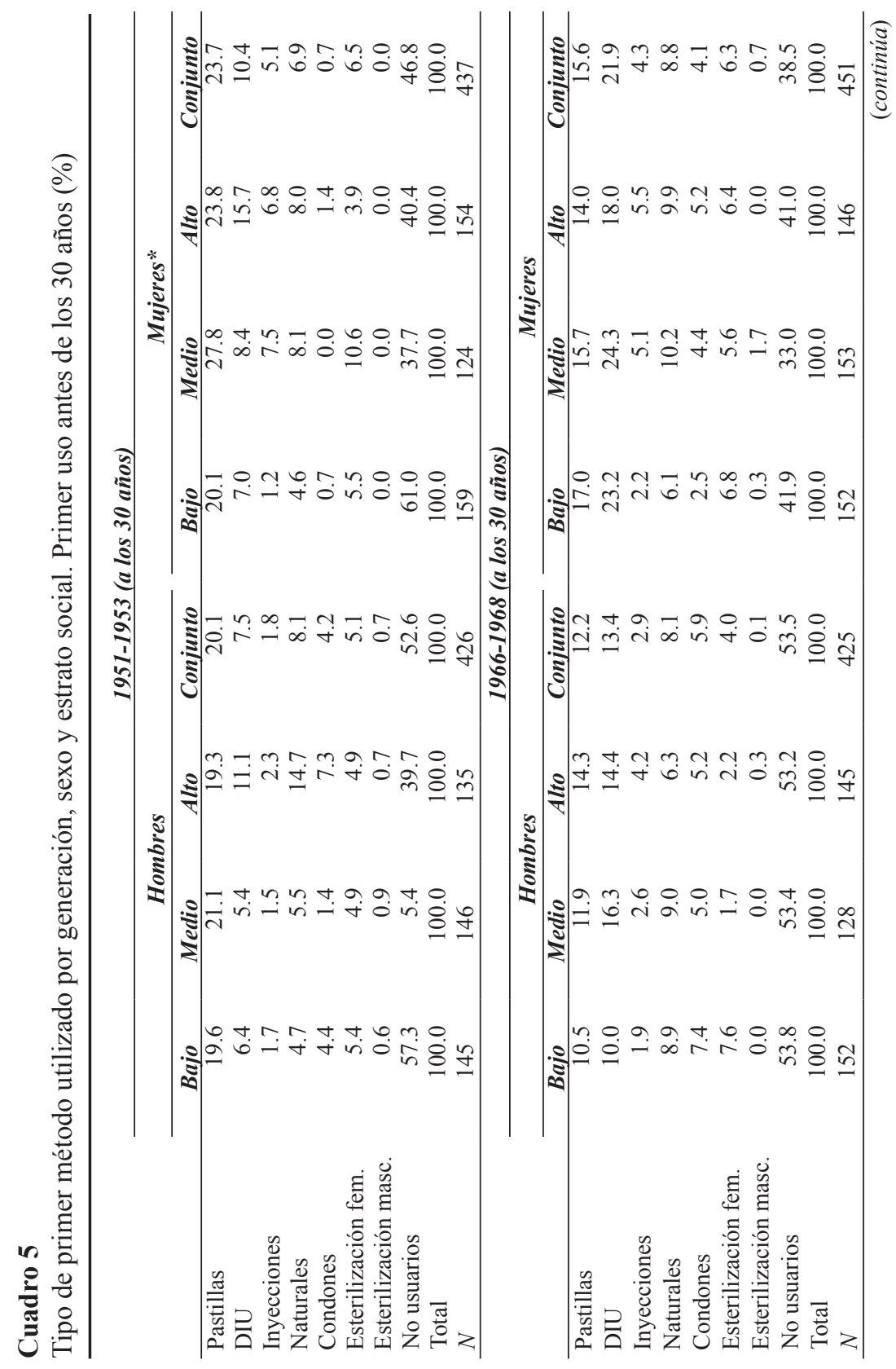




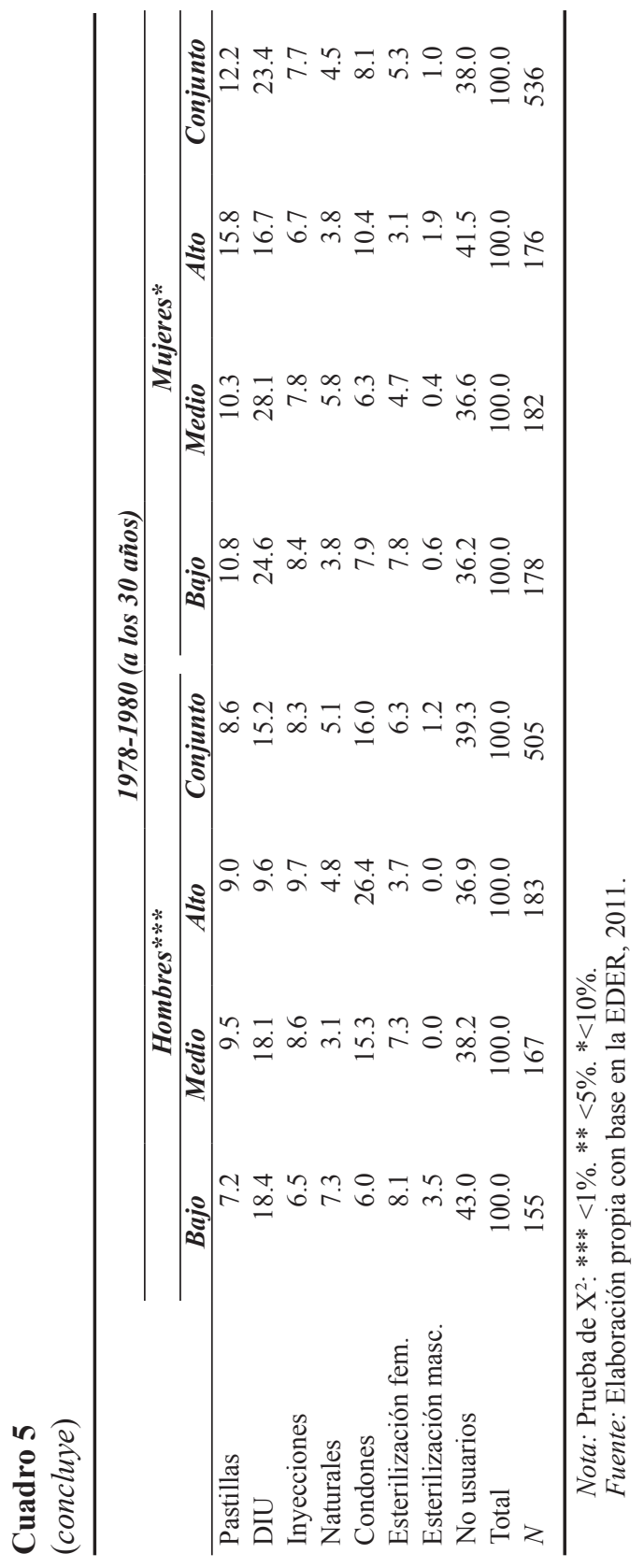


Al analizar con mayor detenimiento estas transformaciones, podemos señalar que en la generación más avanzada (1953-1951), los hombres de los tres estratos declararon haber utilizado principalmente las pastillas. Después, a niveles muy cercanos, el DIU, los métodos naturales y la esterilización femenina. Los hombres de estrato alto muestran una mayor implicación en la práctica anticonceptiva, ya que declararon haber utilizado en mayor medida los métodos naturales y el condón, pero las diferencias no son significativas estadísticamente.

Las mujeres de esta misma generación y de los tres estratos sociales también declararon haber utilizado las pastillas como primer método, seguido en importancia por el DIU, los métodos naturales y la esterilización femenina.

Es notorio que las poblaciones de estrato alto de estas generaciones tuvieran un uso tan importante del DIU (después de las pastillas). Es posible que se haya tratado de una población selectiva que tenía acceso a este tipo de método, muy probablemente en el servicio médico privado, a diferencia de las mujeres de los otros dos estratos sociales. Sin embargo, el DIU tendrá posteriormente una difusión muy importante en todos los sectores sociales, así que en su época estas mujeres podían considerarse a la vanguardia.

La generación intermedia (1966-1968) puede ser considerada como una de transición de las pastillas al DIU. La elevada prevalencia del DIU en esta población indica una clara predominancia de un modelo de control natal regido por una normativa muy medicalizada. La importante y masiva difusión de este método en particular, incidió en los comportamientos y elecciones de las poblaciones de los tres estratos sociales. A pesar de ello, los métodos tradicionales continuaron siendo empleados, aunque con una cada vez menor prevalencia.

En la generación más joven (1978-1980) se aprecia entre los hombres que, aunque sigue teniendo preponderancia el DIU como primer método (dejando atrás a las pastillas, excepto en el estrato alto), el uso del condón se ha incrementado de manera notable en el estrato medio y, sobre todo, en el estrato alto. Esta evolución es muy importante porque brinda elementos para hablar de: una mayor participación masculina en la práctica anticonceptiva; un patrón de comportamiento emergente que se independiza de las normas médicas y sociales prevalecientes; y una nueva normativa en torno a la sexualidad, separada de la vida conyugal y de la procreación.

Entre las mujeres de esta misma generación y en los tres estratos sociales prevalece el uso del DIU como primer método anticonceptivo, seguido de las pastillas. La elevada prevalencia de ambos métodos indica que entre la población femenina, a diferencia de los hombres de su misma generación, prevalece un modelo de control natal todavía muy medicalizado. A pesar de 
ello, el uso del condón va adquiriendo importancia en su experiencia. Sin embargo, en la escasa declaración de las mujeres quizá esté involucrado un problema de subdeclaración, probablemente relacionado con la escasa legitimidad que todavía tiene la existencia de una sexualidad premarital entre ellas, a diferencia de la experiencia masculina en esta materia (Szasz, 2001).

Para entender con mayor precisión estas evoluciones, mediante un análisis de regresión logístico multinomial, estudiamos el efecto de algunas variables sociodemográficas (cohorte, sexo y estrato social en combinación con el nivel de escolaridad) ${ }^{4}$ sobre la probabilidad de utilizar un determinado método anticonceptivo cuando se inicia la práctica anticonceptiva, teniendo como referencia el uso de las pastillas ${ }^{5}$ (Cuadro 6).

Es importante aclarar que, a partir de aquí, el análisis estará circunscrito solamente a los comportamientos de los usuarios de algún método anticonceptivo antes de los 30 años. Además, en este análisis no tomaremos en consideración a los métodos definitivos.

Podemos observar que para los usuarios de la generación más avanzada (1951-1953), respecto a la intermedia (1966-1968), es más probable el empleo de las pastillas antes que cualquier otro método anticonceptivo. Y lo contrario ocurre en las poblaciones más jóvenes (1978-1980), puesto que entre ellas es más probable que se use cualquier otro tipo de método -como el condón, las inyecciones y el DIU- antes que las pastillas. Se trata de un claro efecto de generación entre los usuarios vinculado fuertemente a la dinámica de difusión de la planificación familiar que le tocó vivir a cada generación.

Las mujeres usuarias tienden a declarar menos que los hombres el uso del condón, aunque puede tratarse de un problema de subdeclaración relacionado con la posibilidad de la existencia de una sexualidad premarital entre ellas, cuestión sobre la que hemos comentado antes.

A diferencia de lo que habíamos observado respecto a la propensión de tener un comportamiento novedoso al haber usado un método sin haber tenido hijos, en el caso del tipo de primer método, el estrato social no parece tener un efecto sistemático en los usuarios de algún método. En cambio, se observa un importante efecto de la escolaridad, puesto que el hecho de haber alcanzado el nivel de preparatoria, en cualquier estrato social, favorece el uso del condón como primer método anticonceptivo. Para los usuarios de estrato

${ }^{4}$ El modelo incluye solamente a los usuarios de algún método anticonceptivo, por ello se reduce la población estudiada y, por consiguiente, fue necesario agregar los niveles de escolaridad.

${ }^{5}$ Utilizamos como referencia a las pastillas porque fue el método más difundido a la puesta en marcha del Programa Nacional de Planificación Familiar y, por ello, fue el más utilizado por las poblaciones de la generación más avanzada. 
bajo este efecto es notorio desde el nivel de secundaria. Podemos suponer que la educación escolar en este nivel permite tener información sobre diversos métodos y, en particular, sobre el condón y los mecanismos para conseguirlo. Puede también contribuir a modificar los tabúes sobre su utilización.

\section{Cuadro 6}

Efecto de algunas variables sociodemográficas en la probabilidad de haber usado un tipo de método anticonceptivo por primera vez. Población de alguna vez usuarios. Modelo logístico multinomial. Razones de momios. Referencia: pastillas

\begin{tabular}{|c|c|c|c|c|}
\hline & Condones & $D I U$ & Inyecciones & Naturales \\
\hline \multicolumn{5}{|l|}{ Cohorte } \\
\hline $1951-1953$ & $0.316^{* * *}$ & $0.342^{* * *}$ & $0.587^{*}$ & $0.603^{* *}$ \\
\hline \multicolumn{5}{|l|}{ 1966-1968 (ref.) } \\
\hline $1978-1980$ & $2.969^{* * *}$ & $1.408^{* *}$ & $2.985^{* * *}$ & 0.718 \\
\hline \multicolumn{5}{|l|}{ Sexo } \\
\hline Mujer & $0.415^{* * *}$ & 1.216 & 0.945 & 0.767 \\
\hline \multicolumn{5}{|l|}{ Hombre (ref.) } \\
\hline \multicolumn{5}{|l|}{ Estrato social y escolaridad ${ }^{\text {a }}$} \\
\hline Alto / preparatoria y más & $2.894^{* * *}$ & 1.173 & 1.302 & 1.314 \\
\hline Alto / menos que preparatoria & 1.955 & 1.376 & 1.242 & 1.807 \\
\hline Medio / preparatoria y más & $2.125^{* *}$ & 1.510 & 1.196 & 1.668 \\
\hline Medio / secundaria & 1.251 & $1.593^{*}$ & 1.030 & 1.539 \\
\hline Medio / primaria o sin estudios & 0.908 & 1.499 & 1.474 & 0.793 \\
\hline Bajo / secundaria y más & $1.968^{*}$ & $2.048^{* * *}$ & 0.838 & $1.826^{* *}$ \\
\hline \multicolumn{5}{|l|}{$\begin{array}{l}\text { Bajo / primaria o sin estudios } \\
\text { (ref.) }\end{array}$} \\
\hline $\begin{array}{l}\text { Likelihood ratio }=247.8270 \\
\mathrm{DDL}=36 * * * \\
N=1414\end{array}$ & & & & \\
\hline
\end{tabular}

${ }^{\text {a }}$ El nivel de escolaridad considerado es aquél que se tenía al momento del primer uso de anticoncepción.

$* \mathrm{p}<.05 ; * * \mathrm{p}<.01 ; * * * \mathrm{p}<.001$.

Fuente: Elaboración propia con base en la EDER, 2011.

Por otro lado, un nivel de escolaridad de secundaria asociado a la pertenencia al estrato medio o bajo, tiene un impacto favorable sobre la propensión a usar el DIU antes que las pastillas. Llama la atención, por otro lado, que en los usuarios del estrato bajo con escolaridad de secundaria o más, la probabilidad de utilizar métodos naturales sea mayor que la de usar las pastillas. 
Se mantiene el efecto del estrato social alto y medio, con escolaridad de preparatoria o más, sobre un uso preferencial del condón y después el DIU, antes que las pastillas. En el estrato social bajo, asociado a una escolaridad de secundaria o más, hay una importante propensión a utilizar el DIU antes que las pastillas.

El número de hijos tenidos al momento de usar por primera vez un método anticonceptivo tiene un efecto sobre el tipo de método utilizado, puesto que los usuarios que no han tenido hijos prefieren comenzar su práctica anticonceptiva con el condón antes que con las pastillas. Y entre ellos mismos, es menos probable que usen el DIU que las pastillas. En cambio, entre aquellos que tienen dos hijos o más, es más probable que comiencen a controlar su fecundidad con las inyecciones y menos con métodos naturales que con las pastillas.

\section{Discusión y consideraciones finales}

Nuestros resultados confirman que, al igual que en diversos países de América Latina, en México están ocurriendo importantes transformaciones en términos de la posposición de la fecundidad y de la conformación de las familias, producto de la amplia difusión y legitimación de la práctica anticonceptiva. Sin embargo, tal como ocurre en la región, en México estos cambios son todavía lentos y no muestran una tendencia generalizada, puesto que el calendario de entrada a la reproducción se encuentra segmentado por estratos sociales, ya que hay estratos en los que se comienza a retrasar el comienzo de la formación familiar a edades más avanzadas, y otros en los que la población tiene un comportamiento más proclive al inicio temprano, cuestión que evidencia un escenario de una importante heterogeneidad entre distintos sectores sociales, tal como se ha observado en países como Uruguay o Brasil, por ejemplo.

Sin embargo, los hallazgos de nuestro estudio nos permiten ir más allá de estas constataciones y aportan evidencia sobre los cambios ocurridos en el país respecto a la práctica anticonceptiva y su intervención cada vez más temprana en la formación de las descendencias. Las evoluciones de las que hemos dado cuenta indican que estamos asistiendo a un importante proceso de cambio entre las generaciones mexicanas, puesto que la anticoncepción es cada vez más precoz respecto a los otros eventos de la trayectoria familiar.

Debe notarse, sin embargo, que este cambio está marcado fuertemente por la desigualdad social, ya que son las poblaciones de los estratos sociales más acomodados quienes se encuentran a la vanguardia respecto a estas 
transformaciones, en tanto que las poblaciones de estratos sociales más empobrecidos todavía muestran rezagos.

Si bien la amplia difusión y legitimación de la práctica anticonceptiva ha masificado el uso de los modernos métodos anticonceptivos, ello no ha logrado generalizar la transformación de las normas y las prácticas en torno a la sexualidad, la entrada en unión y la formación familiar en todos los estratos sociales. Continúa siendo preponderante entre la población mexicana el comienzo de la práctica anticonceptiva en el seno de las uniones conyugales y después de haber procreado al menos un hijo. Es todavía poco frecuente que las parejas comiencen a controlar su fecundidad antes de tener a su primer hijo, experiencia que les permitiría tener un espacio importante para la convivencia conyugal sin riesgo de un embarazo. Este hecho indica que continúa estando vigente entre la población mexicana la normativa social que establece un estrecho vínculo entre la entrada en unión y la formación de la descendencia.

A pesar de ello, apreciamos algunos cambios importantes. En todas las generaciones, los hombres y las mujeres con mejores condiciones de vida muestran un deseo por alejarse de las normas sociales y médicas respecto al momento de comenzar su práctica anticonceptiva y en cuanto al tipo de método elegido. En este caso, los hombres de estrato alto, sobre todo de las generaciones más jóvenes, van a la vanguardia en estas evoluciones. Ellos tienden a comenzar su actividad sexual y su práctica anticonceptiva en soltería, es decir, antes de haberse unido y sin haber tenido hijos. Son innovadores no solamente respecto al momento en que inician el control de su fecundidad, sino también en cuanto al tipo de método elegido para ello: el condón.

Apreciamos también importantes diferencias sociales puesto que el estrato social marca, de alguna manera, la mayor o menor distancia con las normas sociales o médicas preponderantes. Por ello, las personas de estrato alto tienden a alejarse con mayor notoriedad de dichas normativas. La escolaridad de preparatoria o más se combina para reforzar estos comportamientos innovadores, puesto que su efecto es notable cualquiera que sea el estrato social. Además, para las personas de estrato medio la escolaridad de secundaria también muestra un efecto importante. Todo ello nos confirma que tanto la escolaridad como la pertenencia a estratos sociales de origen más acomodado favorecen un distanciamiento de las normas sociales tradicionales.

En cuanto a la elección del tipo de primer método anticonceptivo utilizado, detectamos claramente el impacto que ha tenido la política de población, a través de sus programas de planificación familiar, en los usuarios. Se 
ha transitado de la intensa difusión de las pastillas anticonceptivas al empleo del DIU, como métodos que permiten un mayor control médico sobre los cuerpos de las mujeres. Este patrón de control natal medicalizado, sobre todo en la experiencia femenina, sigue siendo preponderante entre las generaciones intermedia y joven, puesto que el DIU y las pastillas continúan siendo los métodos más empleados por ellas.

Sin embargo, la persistencia del uso de los métodos naturales y la emergencia del empleo del condón indican que existe un sector social que parece eludir el control médico, al tiempo que fomenta una activa participación masculina en la práctica anticonceptiva. El uso del condón, en particular, es también signo de un distanciamiento respecto a las normas sociales tradicionales en torno a la vida sexual que la anclaban al ámbito conyugal. Este distanciamiento es fuertemente favorecido por la educación escolar y, de manera más clara, aquella de nivel preparatoria, cualquiera que sea su estrato social. Las personas usuarias que alcanzan este grado de escolarización tienen más recursos, en términos de conocimiento y toma de decisiones, para actuar de manera autónoma frente a las normas sociales y las instituciones de salud.

En esta importante transición, son los hombres más jóvenes de estrato alto quienes llevan la delantera, cuestión que plantea varios temas a discutir, puesto que bien podría estar implicando una participación masculina más equitativa, solidaria y responsable con sus parejas sexuales, protegiéndolas de un posible embarazo. Pero también podría significar que estos hombres buscan protegerse de las infecciones de transmisión sexual, como el VIH-sida, antes que evitar un embarazo durante sus relaciones sexuales prematrimoniales, dentro de la unión o extraconyugales, lo cual plantearía desafíos importantes en materia de equidad de género para las campañas de planificación familiar y los servicios de salud reproductiva. En todo caso, creemos que los estudios cualitativos en este tema podrían contribuir a profundizar y conocer sobre las motivaciones y los significados de esta importante evolución en la sociedad mexicana.

\section{Bibliografía}

Amuchástegui, A. (2001). Virginidad e iniciación sexual en México. Experiencias y significados. México: The Population Council / Edamex.

Bronfman, M., López, E. y Tuirán, R. (1986). Práctica anticonceptiva y clases sociales en México: la experiencia reciente. Estudios Demográficos y Urbanos, 1(2), 165-203. Recuperado de https://estudios demograficosyurbanos.colmex.mx/index.php/edu/article/view/586 
Brugeilles, C. (2005). Tendencias de la práctica anticonceptiva en México: tres generaciones de mujeres. En M. Coubès, M. E. Zavala y R. Zenteno (coords.), Cambio demográfico y social en el México del siglo XX. Una perspectiva de historias de vida (pp. 121-157). México: El Colegio de la Frontera Norte / Porrúa.

Brugeilles, C. (2011). Révolution contraceptive au Mexique. De la volonté divine à celle du médecin? En L. Charton y J. Lévy (coords.), La contraception. Prévalence, prévention et enjeux de société (pp. 121-152). Montreal, Canadá: Presses de l'Université du Québec.

Brugeilles, C. y Rojas, O. (2016). Inicio de la práctica anticonceptiva y formación de las familias. Experiencia de tres cohortes mexicanas. En M. Coubès, P. Solís y M. E. Zavala (coords.), Generaciones, cursos de vida y desigualdad social en México (pp. 161-188). México: El Colegio de México, A.C. / El Colegio de la Frontera Norte.

Brugeilles, C. y Samuel, O. (2005). Formación de parejas y vida fecunda en México. En M. Coubès, M. E. Zavala y R. Zenteno (coords.), Cambio demográfico y social en el México del siglo XX. Una perspectiva de historias de vida (pp. 453-477). México: El Colegio de la Frontera Norte / Porrúa.

CEPAL. (2012). Panorama social de América Latina 2011. Santiago de Chile: Comisión Económica para América Latina y el Caribe. Recuperado de https://www.cepal.org/es/publicaciones/1241-panoramasocial-america-latina-2011

Conapo. (2014). La situación demográfica de México, 2013. Ciudad de México: Consejo Nacional de Población. Recuperado de http://www.conapo. gob.mx/en/Conapo/La_Situacion_Demografica_de_Mexico_2013

Conapo. (2017). La situación demográfica de México, 2016. Ciüdad de México: Consejo Nacional de Población. Recuperado de https://www.gob. $\mathrm{mx} /$ conapo/documentos/la-situacion-demografica-de-mexico-2016

Figueroa, B. (1992). La fecundidad en 1990. El delicado tema de las estimaciones actuales. Demos. Carta Demográfica sobre México, 5, 10-12.

Fostik, A. L., Fernández, M. y Varela, C. (2014). El papel de la paternidad en la transición a la adultez en los varones jóvenes uruguayos. Notas de Población, 98, 11-40, Recuperado de https://repositorio.cepal.org/ bitstream/handle/11362/37707/1/np98011040_es.pdf

García, B. y Oliveira, O. de. (1990). Social sectors and reproduction in Mexico. En M. Bronfman, B. García, F. Juárez, O. de Oliveira y J. Quilodrán (coords.), Social sectors and reproduction in Mexico (pp. 1-3). México: El Colegio de México, A.C. / The Population Council. 
Giddens, A. (1998). La transformación de la intimidad. Sexualidad, amor y erotismo en las sociedades modernas. Madrid, España: Cátedra Teorema. Hernández, D. (2001). Anticoncepción en México. En J. Gómez de León y C. Rabell (coords.), La población en México. Tendencias y perspectivas sociodemográficas hacia el siglo XXI (pp. 271-306). México: Consejo Nacional de Población / Fondo de Cultura Económica.

Juárez, F. y Quilodrán, J. (1990). Mujeres pioneras del cambio reproductivo en México. Revista Mexicana de Sociología, 52(1), 33-49. Recuperado de https://www.jstor.org/stable/3540645?seq=1\#metadata_info_tab_ contents

Juárez, F. y Quilodrán, J. (2009). Las pioneras del cambio reproductivo: un análisis partiendo de sus propios relatos. Notas de Población, 87, 6394. Recuperado de https://repositorio.cepal.org/handle/11362/12841

Juárez, F., Quilodrán, J. y Zavala, M. E. (1989). Les tendances récentes de la fécondité au Mexique (Documento de trabajo núm. 63). París, Francia: Credal.

Le Coeur, S., Im-em, W., Koetsawang, S. y Lelièvre, É. (2005). Living with HIV in Thailand: Assessing vulnerability through a life-event history approach. Population (English Edition), 60(4), 473-488. Recuperado de https://www.cairn-int.info/article-E_POPU_504_0551-living-with-hiv-in-thailand-assessing-vu.htm

Lesthaeghe, R. (1995). The second demographic transition in western countries: An interpretation. En K. Oppenheim y A. Jensen (eds.), Gender and family change in industrialized countries (pp. 17-62). Oxford, Inglaterra: Clarendon Press.

Mier y Terán, M. (2016). La escolaridad, el estrato social y la formación de las primeras uniones en México: una visión de largo plazo. Notas de Población, 102, 301-327. Recuperado de https://www.cepal.org/es/ publicaciones/40269-la-escolaridad-estrato-social-la-formacionprimeras-uniones-mexico-vision-largo

Mier y Terán, M. y Rabell, C. (1984). Fecundidad y grupos sociales en México. En R. Jiménez y A. Minujin (coords.), Los factores del cambio demográfico en México (pp. 221-241). México: Siglo XXI.

Nathan, M. (2015). La creciente heterogeneidad en la edad al primer hijo en el Uruguay: un análisis de las cohortes de 1951 a 1990. Notas de Población, 100, 35-59. Recuperado de https://www.cepal.org/es/ publicaciones/38522-la-creciente-heterogeneidad-la-edad-al-primerhijo-uruguay-un-analisis-cohortes

Páez, O. y Zavala, M. E. (2016). Tendencias y determinantes de la fecundidad en México: las desigualdades sociales. En M. Coubès, P. Solís 
y M. E. Zavala (coords.), Generaciones, cursos de vida y desigualdad social en México (pp. 45-76). México: El Colegio de México, A.C. / El Colegio de la Frontera Norte.

Plummer, K. (2003). Intimate citizenship. Private decisions and public dialogues. Seattle, WA: University of Washington Press.

Reis, N. (2015). Las desigualdades de clase en el comportamiento reproductivo en el Brasil: democratización incompleta y paradojas de la fecundidad juvenil. Notas de Población, 100, 61-89. Recuperado de https://repositorio.cepal.org/bitstream/handle/11362/38523/1/03 Reis_100A.pdf

Solís, P. (2016). De joven a adulto en familia: trayectorias de emancipación familiar en México. En M. Coubès, P. Solís y M. E. Zavala (coords.), Generaciones, cursos de vida y desigualdad social en México (pp. 193-222). México: El Colegio de México, A.C. / El Colegio de la Frontera Norte.

Solís, P., Gayet, C. y Juárez, F. (2008). Las transiciones a la vida sexual, a la unión y a la maternidad en México: cambios en el tiempo y estratificación social. En S. Lerner e I. Szasz (coords.), Salud reproductiva y condiciones de vida en México. Tomo I (pp. 397-428). Ciudad de México: El Colegio de México, A.C.

Szasz, I. (2001). La investigación sobre sexualidad y el debate sobre los derechos reproductivos en México. En J. Gómez de León y C. Rabell (coords.), La población de México. Tendencias y perspectivas sociodemográficas hacia el siglo XXI (pp. 365-397). Ciudad de México: Conapo / Fondo de Cultura Económica.

Szasz, I. (2008). Relaciones de género y desigualdad socioeconómica en la construcción social de las normas sobre la sexualidad en México. En S. Lerner e I. Szasz (coords.), Salud reproductiva y condiciones de vida en México. Tomo I (pp. 431-475). Ciudad de México: El Colegio de México, A.C.

Tuirán, R. (1994). Familia y sociedad en el México contemporáneo. Saber Ver. Lo Contemporáneo del Arte, número especial, 33-55.

Urbina, M., Palma, Y., Figueroa, J. G. y Castro, P. (1984). Fecundidad, anticoncepción y planificación familiar en México. Comercio Exterior, 34(7), 647-666. Recuperado de http://revistas.bancomext.gob.mx/rce/ magazines/224/7/RCE7.pdf

Welti, C. (2005). Inicio de la vida sexual y reproductiva en México. Papeles de Población, 11(45), 143-176. Recuperado de https://www.redalyc. org/pdf/112/11204507.pdf

Zavala, M. E. (1992). Cambios de fecundidad en México y políticas de población. Ciudad de México: El Colegio de México, A.C. / Fondo de Cultura Económica.

Estudios Demográficos y Urbanos, vol. 35, núm. 2 (104), mayo-agosto, 2020, pp. 293-332

http://dx.doi.org/10.24201/edu.v35i2.1847 
Zavala, M. E.(1996). Malthusianisme de la pauvreté au Mexique. En H. Leridon (dir.), Populations: l'etat des connaissances (pp. 245-256). París, Francia: La Découverte.

Zavala, M. E. (2005). Las tendencias de la fecundidad en los grupos de generaciones urbanas y rurales según el sexo. En M. Coubès, M. E. Zavala y R. Zenteno (coords.), Cambio demográfico y social en el México del siglo XX. Una perspectiva de historias de vida (pp. 97-119). México: El Colegio de la Frontera Norte / Tecnológico de Monterrey / Porrúa/ Cámara de Diputados.

\section{Acerca de las autoras}

Carole Brugeilles es profesora-investigadora de Demografía en la Université Paris Nanterre y directora adjunta del Centro de Investigación Sociológica y Política de París (Cresppa-UMR 7217). Sus temas de investigación son: las transiciones demográficas y los cambios en los comportamientos reproductivos, las políticas de población, la salud reproductiva, la socialización en la niñez y la adolescencia en la familia y la escuela, así como la sociodemografía de género. Coordinó el Programa Internacional Nacimientos Mexicanos en colaboración con El Colegio de México, A.C. y el Centre d'Études Mexicaines et Centraméricaines (CEMCA).ORCID: https://orcid. org/0000-0001-6813-0467

Olga Lorena Rojas es licenciada en Sociología por la Universidad Autónoma Metropolitana, maestra en Demografía y doctora en Estudios de Población por El Colegio de México, institución donde labora como profesora-investigadora desde hace más de diez años. Ha sido profesora en diversas instituciones de educación superior, como la Universidad Autónoma Metropolitana y El Colegio de la Frontera Norte. Es miembro del Sistema Nacional de Investigadores, nivel III. Sus temas de interés en la investigación están relacionados con el género, la familia y la reproducción, sobre los que ha publicado diversos artículos y capítulos de libros. Es autora de los libros Paternidad y vida familiar en la Ciudad de México y Estudios sobre la reproducción masculina, ambos publicados por El Colegio de México, A.C. ORCID: https://orcid.org/0000-0002-5374-5378

Recepción: 26 de febrero de 2018.

Aceptación: 9 de enero de 2019. 